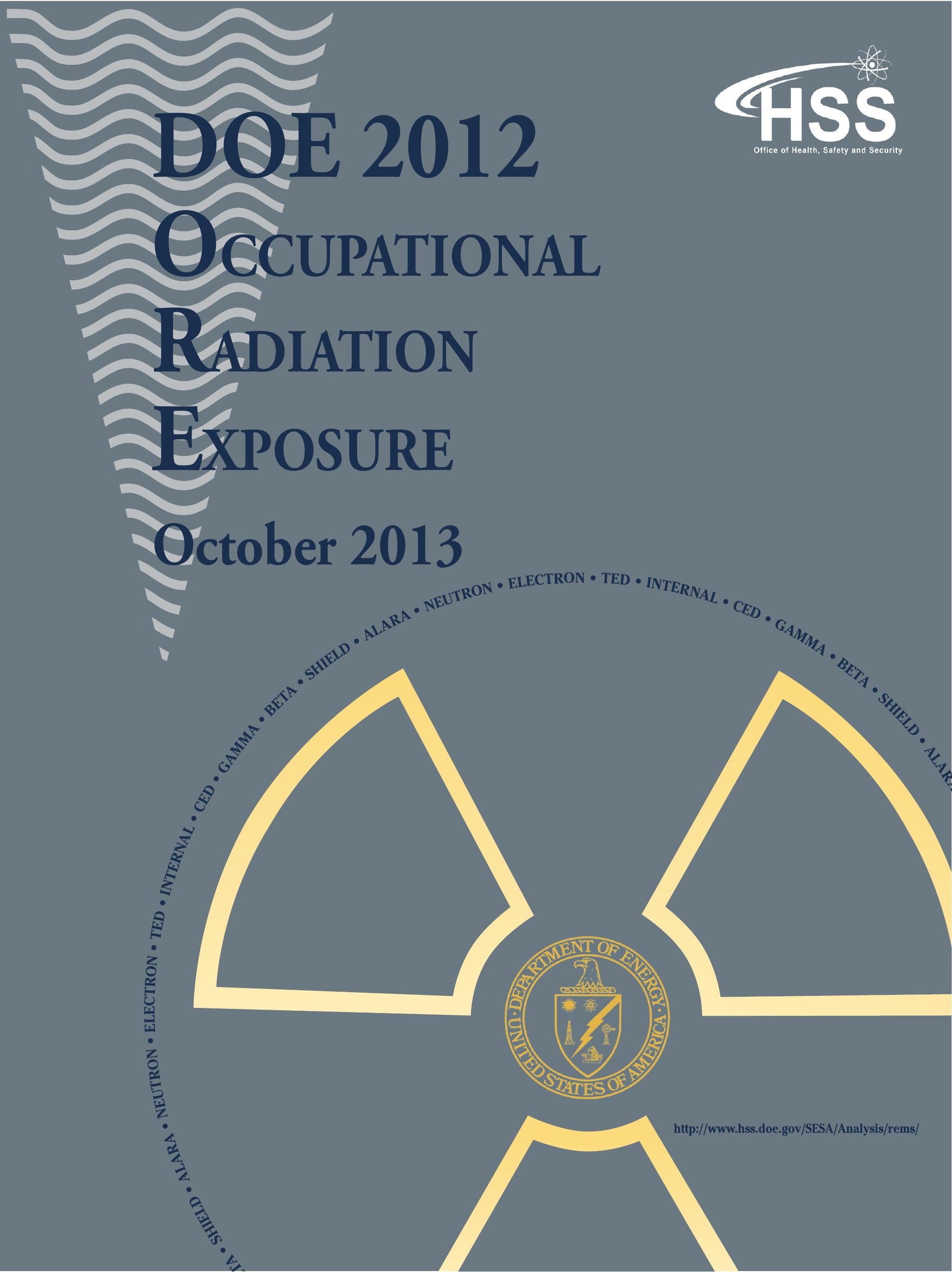


This document is available on the Department of Energy

REMS Program Web Site at:

http://www.hss.doe.gov/SESA/Analysis/rems/ 
A core value of the U.S. Department of Energy (DOE) is to ensure the health and safety of DOE employees, contractors, and subcontractors. The Office of Health, Safety and Security (HSS) provides the corporate-level leadership and strategic vision necessary to establish clear expectations for and provide oversight and enforcement regarding health, safety, environment, and security programs. In support of this mission, the HSS Office of Analysis provides for the collection, analysis, and dissemination of data and performance indicators, such as occupational radiation exposure information.

A key safety focus for DOE is to maintain worker radiation exposures below administrative control levels and DOE radiation dose limits and to further reduce these exposures to levels that are "as low as reasonably achievable (ALARA)." The annual DOE 2012 Occupational Radiation Exposure Report provides an evaluation of DOE-wide performance regarding compliance with Title 10, Code of Federal Regulations, Part 835, Occupational Radiation Protection dose limits and ALARA process requirements and an overview of the status of radiation exposures of the DOE workforce. In addition, this report serves as a risk management tool for managing radiological safety programs and provides useful information to DOE organizations, epidemiologists, researchers, and national and international agencies involved in developing policies to protect individuals from harmful effects of radiation.

The Radiation Exposure Monitoring System program remains a key component of HSS oversight and analysis to inform management and stakeholders of the continued vigilance and success of the DOE sites in minimizing radiation exposure to workers. One of the objectives of this report is to provide useful, accurate, and complete information to DOE and the public. As part of a continuing improvement process, we would appreciate your response to the User Survey included at the end of this report. 
This page intentionally left blank. 


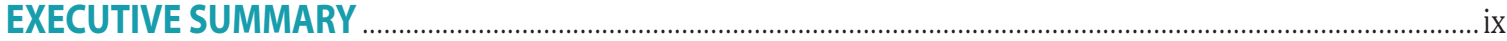

\section{SECTION 1-INTRODUCTION}

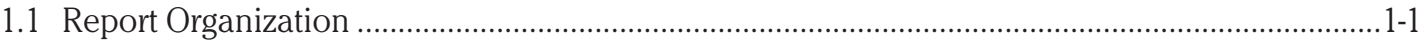

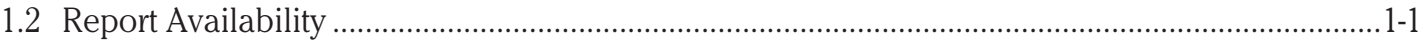

\section{SECTION 2-STANDARDS AND REQUIREMENTS}

2.1 Radiation Protection Requirements ......................................................................................... $2-1$

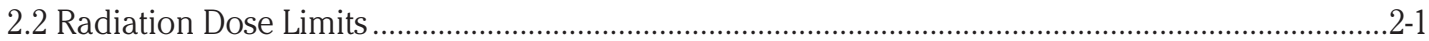

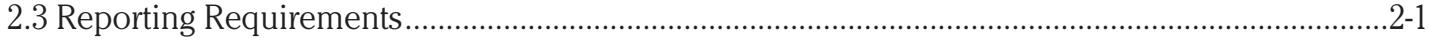

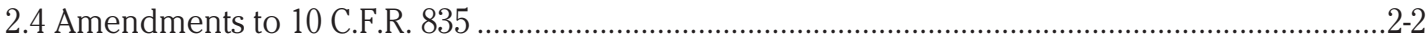

SECTION 3-OCCUPATIONAL RADIATION DOSE AT DOE

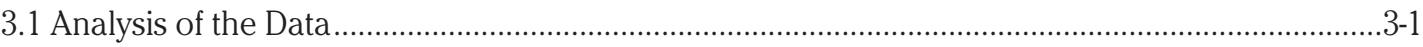

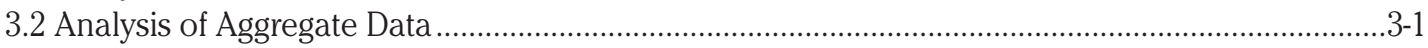

3.2.1 Number of Records for Monitored Individuals ...................................................................

3.2.2 Number of Records for Individuals with Measurable Dose ....................................................3-1

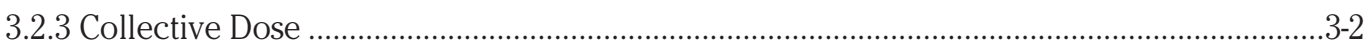

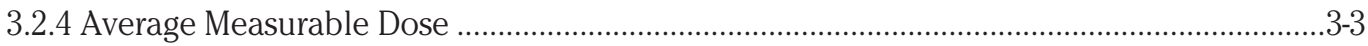

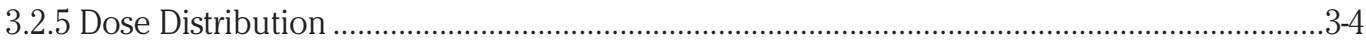

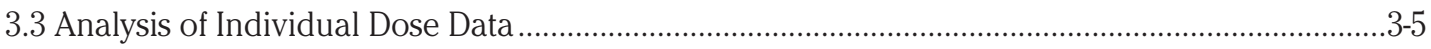

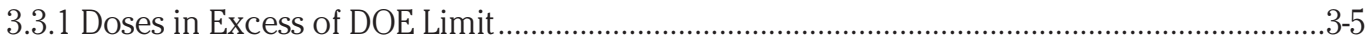

3.3.2 Doses in Excess of Administrative Control Level ...............................................................

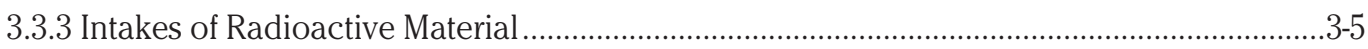

3.3.4 Bioassay and Intake Summary Information ....................................................................

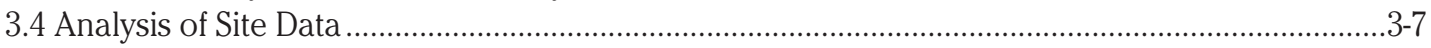

3.4.1 Collective TED by Site and Other Facilities .......................................................................

3.4.2 Changes by Site from 2011 to 2012 ..................................................................................

3.4.3 Activities Significantly Contributing to Collective Dose in 2012 ...........................................3-11

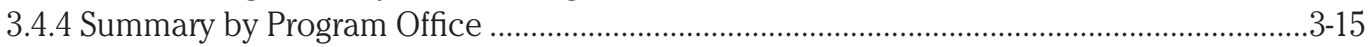

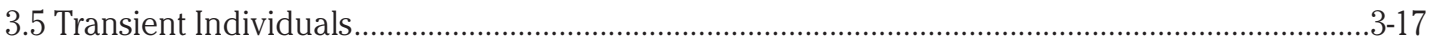

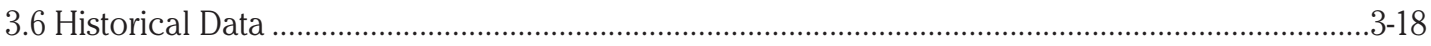

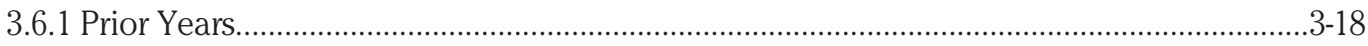

3.6.2 Historical Data Collection................................................................................................... $3-18$

3.7 DOE Occupational Dose in Relation to Other Activities..................................................................3-18

3.7.1 Activities Regulated by the U.S. Nuclear Regulatory Commission.........................................3-18

\section{SECTION 4-ALARA ACTIVITIES AT DOE}

4.1 Submitting ALARA Project Descriptions for Future Annual Reports

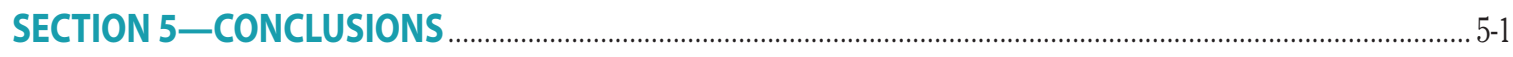

SECTION 6-ADDITIONAL SITE DESCRIPTIONS _..................................................................................... 6-1

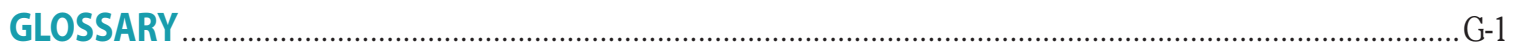

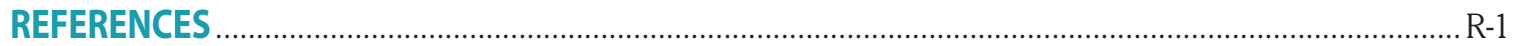

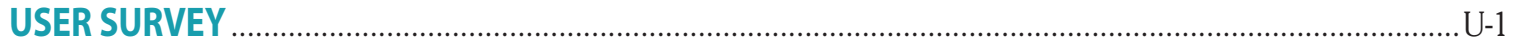




\section{LIST OF EXHIBITS}

Exhibit ES-1: Collective TED (person-rem), 2008-2012 ……………….............................................................

Exhibit ES-2: Average Measurable TED (rem), 2008-2012 . ................................................................................

Exhibit 2-1: $\quad$ Laws and Requirements Pertaining to the Collection and Reporting of Radiation Exposures.............2-1

Exhibit 2-2: $\quad$ DOE Dose Limits from 10 C.F.R. 835

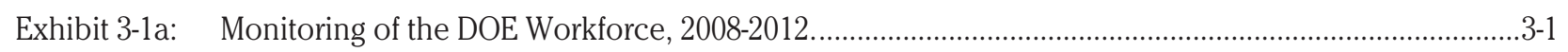

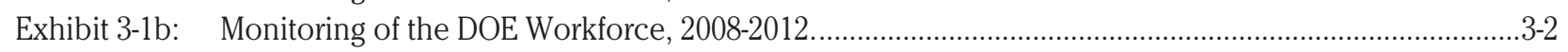

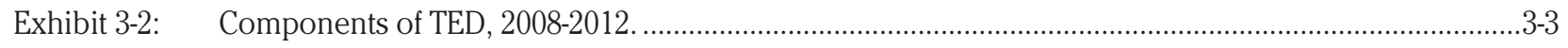

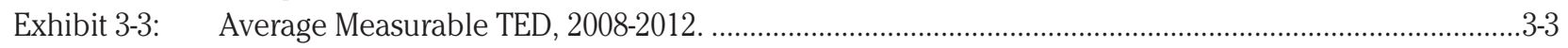

Exhibit 3-4: $\quad$ Distribution of TED by Dose Range, 2008-2012 …........................................................................ 3-4

Exhibit 3-5: $\quad$ Percentage of Individuals with Measurable TED by Dose Range, 2008-2012 .......................................3-4

Exhibit 3-6: $\quad$ Number of Individuals Exceeding 2 rems ACL and the 5 rems Annual Limit, 2008-2012 ....................3-5

Exhibit 3-7: $\quad$ Dose in Excess of DOE Administrative Control Levels, 2008-2012 …….................................................3-6

Exhibit 3-8: $\quad$ Number of Internal Depositions, Collective CED, and Average Measurable CED, 2008-2012 ...............3-6

Exhibit 3-9: Internal Dose Distribution from Intakes, 2008-2012 _.........................................................................

Exhibit 3-10: Bioassay and Air Sampling Measurements, 2010-2012 _...........................................................................3-7

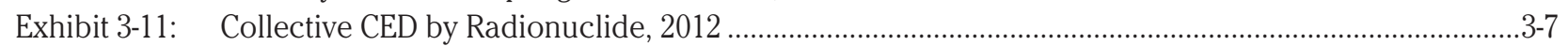

Exhibit 3-12: Collective TED by DOE Site for 2010-2012 _............................................................................................... $3-8$

Exhibit 3-13: Collective TED and Number of Individuals with Measurable TED by DOE Site, 2010-2012................3-9

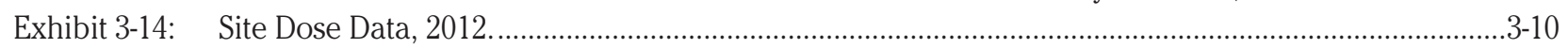

Exhibit 3-15: Activities Significantly Contributing to Collective TED in 2012. ..........................................................3-11

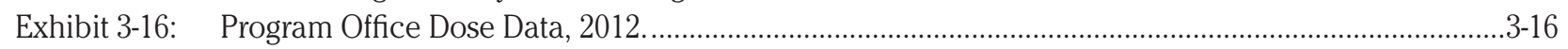

Exhibit 3-17: $\quad$ Dose Distribution of Transient Workers, 2008-2012 …....................................................................... 3-17

Exhibit 3-18: Collective Dose and Average Measurable Dose, 1974-2012 . .............................................................3-19

Exhibit 3-19: $\quad$ Number of Workers with Measurable Dose and Average Measurable Dose, 1974-2012 ......................3-19

Exhibit 3-20: Comparison of Occupational Exposure for DOE and NRC, 2008-2012 .............................................3-20

Exhibit 5-1: 2012 Radiation Exposures Summary ............................................................................................. 5-1 
LIST OF ACRONYMS

ACL

ALARA

AMWTP

ANL

ARRA

BNL

CED

C.F.R.

D\&D

DOE

ED

EM

$\mathrm{EqD}$

ETEC

ETTP

FACET

Fermilab

HSS

ICP

ICRP

INL

KCP

LANL

LATA

LBNL

LLNL

LLNS

$\mathrm{mSv}$

NBL

NNSA

NNSS

NRC

NREL

ORISE

ORNL

ORP

ORPS

PGDP

PNNL

PORTS

PPPL

$\mathrm{Pu}$

RCS

Rem

REMS

$\mathrm{SC}$

SLAC

SNL

SPRU

SRNS
Administrative Control Level

As Low As Reasonably Achievable

Advanced Mixed Waste Treatment Project

Argonne National Laboratory

American Recovery and Reinvestment Act

Brookhaven National Laboratory

Committed Effective Dose

Code of Federal Regulations

Decontamination and Decommissioning

U.S. Department of Energy

Effective Dose

Office of Environmental Management

Equivalent Dose

Energy Technology Engineering Center

East Tennessee Technology Park

Facilities for Accelerator Science and Experimental Test

Fermi National Accelerator Laboratory

Office of Health, Safety and Security

Idaho Cleanup Project

International Commission on Radiological Protection

Idaho National Laboratory

Kansas City Plant

Los Alamos National Laboratory

Los Alamos Technical Associates

Lawrence Berkeley National Laboratory

Lawrence Livermore National Laboratory

Lawrence Livermore National Security, LLC

Millisievert

New Brunswick Laboratory

National Nuclear Security Administration

Nevada National Security Site

U. S. Nuclear Regulatory Commission

National Renewable Energy Laboratory

Oak Ridge Institute for Science and Education

Oak Ridge National Laboratory

Office of River Protection

Occurrence Reporting and Processing System

Paducah Gaseous Diffusion Plant

Pacific Northwest National Laboratory

Portsmouth Gaseous Diffusion Plant

Princeton Plasma Physics Laboratory

Plutonium

Radiological Control Standard

Roentgen equivalent in man

Radiation Exposure Monitoring System

Office of Science

SLAC National Accelerator Laboratory

Sandia National Laboratories

Separations Process Research Unit

Savannah River Nuclear Solutions 
SRR

SRS

SST

$\mathrm{Sv}$

TED

TJNAF

TRU

UCOR

UMTRA

WIPP

WVDP

Y-12
Savannah River Remediation

Savannah River Site

Swift \& Staley

Sieverts

Total Effective Dose

Thomas Jefferson National Accelerator Facility

Transuranic

URS/CH2M Oak Ridge, LLC

Uranium Mill Tailings Remediation Action Project

Waste Isolation Pilot Plant

West Valley Demonstration Project

Y-12 National Security Complex 


\section{Executivesummary 10 y}

The U.S. Department of Energy (DOE) Office of Analysis within the Office of Health, Safety and Security (HSS) publishes the annual DOE Occupational Radiation Exposure Report to provide an overview of the status of radiation protection practices at DOE (including the National Nuclear Security Administration [NNSA]). The DOE 2012 Occupational Radiation Exposure Report provides an evaluation of DOE-wide performance regarding compliance with Title 10, Code of Federal Regulations (C.F.R.), Part 835, Occupational Radiation Protection dose limits and as low as reasonably achievable (ALARA) process requirements. In addition, the report provides data to DOE organizations responsible for developing policies for protection of individuals from the adverse health effects of radiation. The report provides a summary and an analysis of occupational radiation exposure information from the monitoring of individuals involved in DOE activities. Over the past 5-year period, the occupational radiation exposure information is analyzed in terms of aggregate data, dose to individuals, and dose by site.

As an indicator of the overall amount of radiation dose received during the conduct of operations at DOE, the report includes information on collective total effective dose (TED). The TED is comprised of the effective dose (ED) from external sources, which includes neutron and photon radiation, and the internal committed effective dose (CED), which results from the intake of radioactive material into the body. The collective ED from photon exposure decreased by $23 \%$ between 2011 and 2012, while the neutron dose increased by $5 \%$. The internal dose components of the collective TED decreased by 7\%. Over the past 5-year period, 99.99\% of the individuals receiving measurable TED have received doses below the 2 roentgen equivalent in man (rems) (20 millisievert [mSv]) TED administrative control level (ACL), which is well below the DOE regulatory limit of 5 rems (50 mSv) TED annually.

The occupational radiation exposure records show that in 2012, DOE facilities continued to comply with DOE dose limits and ACLs and worked to minimize exposure to individuals. The DOE collective TED decreased 17.1\% from 2011 to 2012, as shown in Exhibit ES-1. The collective TED decreased at three of the five sites with the largest collective TED.

- Idaho Site - Collective dose reductions were achieved as a result of continuing improvements at the Advanced Mixed Waste Treatment Project (AMWTP) through the planning of drum movements that reduced the number of times a container is handled; placement of waste containers that created highradiation areas in a centralized location; and increased worker awareness of high-dose rate areas. In addition, Idaho had the largest decrease in the total number of workers with measurable TED $(1,143$ fewer workers).

$\checkmark$ Hanford Site (Hanford) - An overall reduction of decontamination and decommissioning (D\&D) activities at the Plutonium Finishing Plant (PFP) and Transuranic (TRU) retrieval activities resulted in collective dose reductions.

- Savannah River Site (SRS) - Reductions were achieved through ALARA initiatives employed site wide. The Solid Waste Management Facility used extended specialty tools, cameras and lead shield walls to facilitate removal of drums. These tools and techniques reduce exposure time through improved efficiency, increase distance from the source of radiation by remote monitoring, shield the workers to lower the dose rate, and reduce the potential for contamination and release of material through repacking of waste.

Overall, from 2011 to 2012, there was a 19\% decrease in the number of workers with measurable dose. Furthermore, due to a slight decrease in both the DOE workforce (7\%) and monitored workers (10\%), the ratio of workers with measurable doses to monitored workers decreased to $13 \%$. Another primary indicator of the level of radiation exposure covered in this report is the average measurable dose, which normalizes the collective dose over the population of workers who actually received a measurable dose. The average measurable TED increased by 3\% from 2011 to 2012, as shown in Exhibit ES-2. 
Exhibit ES-1:

Collective TED (person-rem), 2008-2012.

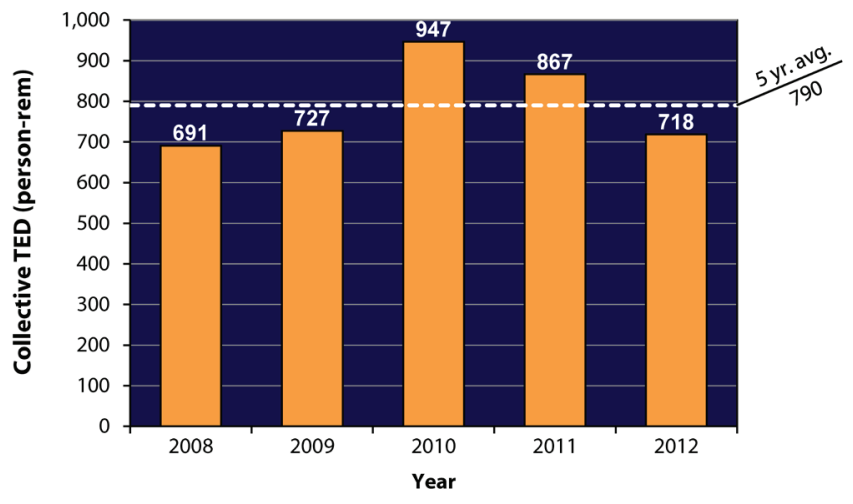

| Exhibit ES-2:

Average Measurable TED (rem), 2008-2012.

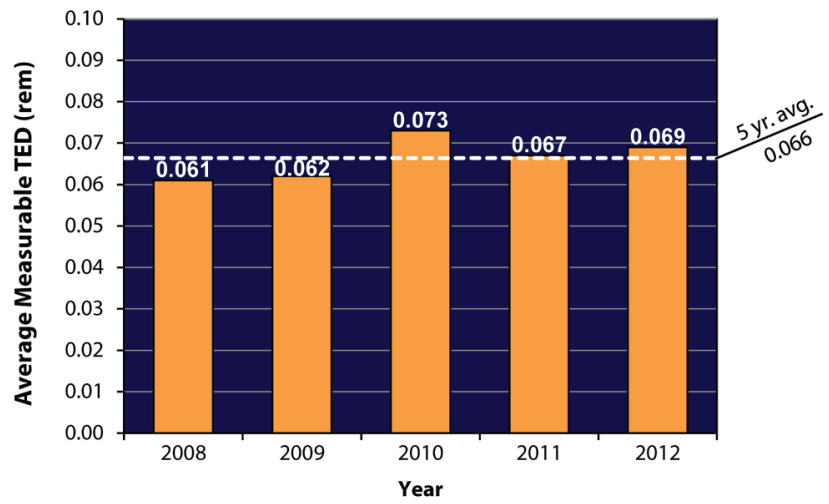

Additional analyses show that the dose distribution in 2012 was similar to the distribution in 2011.

In 2012, 13\% of the monitored workers received a measurable TED and the average measurable TED, 0.069 rem, was less than $2 \%$ of the DOE limit.

From 2011 to 2012, the collective TED and the number of individuals with measurable TED decreased 17.1\% and 19\%, respectively. These decreases were mainly due to an overall reduction of D\&D activities at the PFP and TRU retrieval activities at Hanford; a 78\% decrease in the number of targeted waste drums that were processed at the Idaho Site's Accelerated Retrieval Project (ARP) from 5,566 drums in 2011 to a total of 1,211 drums processed in 2012; and ALARA initiatives employed site wide at SRS. In addition, the decreases were the result of decreased American Recovery and Reinvestment Act (ARRA) activities and continuing D\&D, particularly at the DOE sites that comprise the majority of DOE collective dose.

Over the past 5 years, the size of the monitored workforce has remained at a fairly stable level (within 12\%), while the collective dose has varied up to $37 \%$.

No reported doses exceeded the DOE occupational limit of 5 rems TED in 2012 and no reported doses exceeded the DOE ACL of 2 rems TED.

To access this report and other information on occupational radiation exposure at DOE, visit the DOE HSS web site at:

http://www.hss.doe.gov/SESA/Analysis/rems/ 
The DOE 2012 Occupational Radiation Exposure Report analyzes occupational radiation exposures at U.S. Department of Energy (DOE) facilities during 2012. This report includes occupational radiation exposure information for all DOE employees, contractors, and subcontractors, as well as members of the public in controlled areas that are monitored for exposure to radiation. The $94 \mathrm{DOE}$ organizations submitting radiation exposure reports for 2012 have been grouped into 32 sites. This information has been analyzed and trends over time are presented to provide a measure of DOE's performance in protecting its workers from radiation.

\subsection{Report Organization}

This report is organized into the six sections listed below. Additional supporting technical information, tables of data, and additional items are available on the DOE web site for Information on Occupational Radiation Exposure as appendices to this report (http://www.hss.doe.gov/ $\mathrm{SESA} /$ Analysis/rems). A User Survey form is included at the end of this report and users are encouraged to provide feedback to improve this report.

\subsection{Report Availability}

This report is available online and may be downloaded from:

http://www.hss.doe.gov/SESA/Analysis/rems/
Requests for additional copies of this report, for access to the data files, or for individual dose records used to compile this report, as well as suggestions and comments, should be directed to:

Ms. Nirmala Rao, Office of Analysis (HS-24)

DOE REMS Project Manager

U.S. Department of Energy

1000 Independence Avenue, SW

Washington, D.C. 20585-1290

E-mail: nimi.rao@hq.doe.gov

Visit the DOE web site for more information on occupational radiation exposure, such as the following:

Annual occupational radiation exposure reports in PDF files since 1974;

- Guidance on reporting radiation exposure information to the DOE Headquarters Radiation Exposure Monitoring System (REMS);

$\checkmark$ Guidance on how to request a dose history for an individual;

- Statistical data since 1987 for analysis;

- Applicable DOE orders and manuals for the recordkeeping and reporting of occupational radiation exposure at DOE; and

ALARA activities at DOE.
Section One
Describes the content and organization of this report.
Section Two
Discusses the radiation protection and dose reporting requirements.
Section Three
Presents the 2012 occupational radiation dose data along with trends over the past 5 years.
Section Four
Provides instructions to submit successful as low as reasonably achievable (ALARA) projects.
Section Five
Discusses conclusions.
Section Six
Discusses additional site descriptions.
Appendices
The appendices are offered in color on the DOE Radiation Exposure web site. Please visit http://www.hss.doe.gov/SESA/Analysis/rems/ and select Annual Reports to review. The appendices provide a comprehensive breakdown of dose by field office and site, as well as distributions by facility type and occupation, type of dose, and internal dose by radionuclide. 
This page intentionally left blank. 


\section{standards and Requirements}

One of DOE's primary objectives is to provide a safe and healthy workplace for all employees and contractors. To meet this objective, the DOE Office of Health, Safety and Security (HSS) establishes comprehensive and integrated programs for the protection of workers from hazards in the workplace, including ionizing radiation. The basic DOE standards for occupational radiation protection include radiation dose limits that establish maximum permissible doses to workers. In addition to the requirement that radiation doses not exceed these limits, contractors and subcontractors are required to maintain exposures at ALARA levels.

This section discusses the radiation protection standards and requirements in effect for 2012. For more information on past requirements, visit the DOE web site for DOE Directives, Delegations, and Requirements at https://www.directives.doe.gov/. See Archives section under the Directives menu for historical references.

\subsection{Radiation Protection Requirements}

DOE radiation protection standards in effect at the beginning of 2012 were originally based on Federal guidance for protection against occupational radiation exposure promulgated by the U.S. Environmental Protection Agency in 1987 [1]. This guidance, initially implemented by DOE in 1989, is based on the 1977 recommendations of the International Commission on Radiological Protection (ICRP) Publication 26 [2] and the 1987 recommendations of the National Council on Radiation Protection and Measurements Publication 91 [3]. This guidance recommends that internal dose be added to the external whole-body dose to determine the total effective dose equivalent (TEDE). Prior to this guidance, the external dose and internal dose were each limited separately. It should be noted that Title 10 Code of Federal Regulations (C.F.R.), Part 835, Occupational Radiation Protection was revised in June 2007, with full implementation required by July 2010. The revision adopted ICRP Publications 60 [4] and 68 [5] dosimetric quantities and units (see Section 2.4, Amendment to 10 C.F.R. 835). Title 10 C.F.R. 835 was further revised in April 2011 when Appendix $\mathrm{C}$ was updated. The laws and requirements for occupational radiation protection pertaining to the information collected and presented in this report are summarized in Exhibit 2-1.

\subsection{Radiation Dose Limits}

Radiation dose limits are codified in 10 C.F.R. 835.202, 206, 207, and 208 [6] and are summarized in Exhibit 2-2.

\subsection{Reporting Requirements}

On June 27, 2011, DOE Order (O) 231.1A was updated and reissued as DOE O 231.1B [7]. DOE Manual (M) 231.1-1A, Environment, Safety, and Health Reporting Manual, has been cancelled and the reporting requirements from the manual have been moved to the online REMS Reporting Guide at http://www.hss.doe.gov/sesa/Analysis/rems/ REMS_Reporting_Guide.pdf. [8]

Exhibit 2-1:

Laws and Requirements Pertaining to the Collection and Reporting of Radiation Exposures.

\begin{tabular}{l|l|l|}
\multicolumn{1}{c|}{ Title } & \multicolumn{1}{c|}{ Date } & \multicolumn{1}{c|}{ Description } \\
\hline $\begin{array}{l}\text { 10 C.F.R. 835, Occupational } \\
\text { Radiation Protection [6] }\end{array}$ & $\begin{array}{l}\text { Issued 12/14/93 } \\
\text { Amended 11/4/98 } \\
\text { Amended 6/8/07 } \\
\text { Amended 4/13/11 }\end{array}$ & $\begin{array}{l}\text { Establishes radiation protection standards, limits, and } \\
\text { program requirements for protecting individuals from } \\
\text { ionizing radiation that results from the conduct of DOE } \\
\text { activities. }\end{array}$ \\
$\begin{array}{l}\text { DOE Order 231.1B, } \\
\text { Environment, Safety and } \\
\text { Health Reporting [7] }\end{array}$ & Approved 6/27/11 & $\begin{array}{l}\text { Requires the annual reporting of occupational radiation } \\
\text { exposure records to the DOE REMS repository. }\end{array}$ \\
$\begin{array}{l}\text { REMS Reporting Guide [8] } \\
\text { Issued 2/23/12 }\end{array}$ & $\begin{array}{l}\text { Specifies the current format and content of the reports } \\
\text { required by DOE Order 231.1B. }\end{array}$ \\
\hline
\end{tabular}


Exhibit 2-2:

DOE Dose Limits from 10 C.F.R. 835.

\begin{tabular}{|c|c|c|c|c|}
\hline $\begin{array}{l}\text { Personnel } \\
\text { Category }\end{array}$ & $\begin{array}{c}\text { Section of } \\
10 \text { C.F.R. } \\
835\end{array}$ & Type of Exposure & Acronym & $\begin{array}{c}\text { Annual } \\
\text { Limit }\end{array}$ \\
\hline \multirow{4}{*}{$\begin{array}{l}\text { General } \\
\text { employees }\end{array}$} & \multirow[t]{4}{*}{835.202} & Total effective dose & TED & 5 rems \\
\hline & & $\begin{array}{l}\text { The sum of the effective dose to the } \\
\text { whole body for external exposures } \\
\text { and the committed equivalent dose to } \\
\text { the maximally exposed organ or tissue } \\
\text { other than the skin or the lens of the } \\
\text { eye (Total Organ Dose) }\end{array}$ & $\begin{array}{l}\text { ED+CEqD } \\
\text { (TOD) }\end{array}$ & 50 rems \\
\hline & & Equivalent Dose to the Lens of the Eye & EqD-Eye & 15 rems \\
\hline & & $\begin{array}{l}\text { The sum of the equivalent dose } \\
\text { to the skin or to any extremity for } \\
\text { external exposures and the committed } \\
\text { equivalent dose to the skin or to any } \\
\text { extremity }\end{array}$ & $\begin{array}{l}\text { EqD-SkWB + CEqD-SK } \\
\text { and } \\
\text { EqD to the maximally } \\
\text { exposed extremity + CEqD-SK }\end{array}$ & 50 rems \\
\hline $\begin{array}{l}\text { Declared } \\
\text { pregnant } \\
\text { workers* }\end{array}$ & 835.206 & Total effective dose & TED & $\begin{array}{l}0.5 \text { rem per } \\
\text { gestation } \\
\text { period }\end{array}$ \\
\hline Minors & 835.207 & Total effective dose & TED & $0.1 \mathrm{rem}$ \\
\hline $\begin{array}{l}\text { Members of } \\
\text { the public in a } \\
\text { controlled area }\end{array}$ & 835.208 & Total effective dose & TED & $0.1 \mathrm{rem}$ \\
\hline
\end{tabular}

*Limit applies to the embryo/fetus.

\subsection{Amendment to 10 C.F.R. 835}

In August 2006, DOE published a proposed amendment to 10 C.F.R. 835 in the Federal Register, and in June 2007, the final amended rule was published. The amendment:

Specified new dosimetric terminology and quantities based on ICRP 60/68 in place of ICRP 26/30;

Specified ICRP 60 tissue weighting factors in place of ICRP 26 weighting factors;

- Specified ICRP 60 radiation weighting factors in place of ICRP 26 quality factors;

Amended other parts of the regulation that changed as a result of adopting ICRP 60 dosimetry system;
Used the ICRP 68 dose conversion factors to determine values for the derived air concentrations (DACs); and

- Adopted other changes intended to enhance radiation protection.

The amended rule became effective on July 9, 2007, and was required to be fully implemented by DOE sites by July 9, 2010. Because all sites began complying with the new requirements during 2010, all terminology used in this annual report reflects that of the Amendment. In addition, 10 C.F.R. 835 was revised in April 2011 when Appendix C (Derived Air Concentration for Workers) was updated. 


\section{Occupational Radiation Dose at DOE}

\subsection{Analysis of the Data}

Certain key indicators are useful when evaluating occupational radiation exposures received at DOE facilities. The key indicators are analyzed to identify and correlate parameters having an impact on radiation dose at DOE.

Key indicators for the analysis of aggregate data are the following:
number of records for monitored individuals;
$\checkmark$ individuals with measurable dose;
collective dose;
$\checkmark$ average measurable dose; and
$\checkmark$ dose distribution.

Analysis of individual dose data includes an examination of:

$\checkmark$ doses exceeding the 5 rems (50 millisievert [mSv]) DOE regulatory limit; and

$\checkmark$ doses exceeding the 2 rems (20 mSv) DOE Administrative Control Level (ACL), as specified in DOE STD 1098-2008 Radiological Control.

Additional information is provided in this report concerning activities at sites contributing to the majority of the collective dose. The data for prior years contained in this report are subject to change because sites may submit corrections or additions for previous years.

\subsection{Analysis of Aggregate Data}

\subsubsection{Number of Records for Monitored Individuals}

The number of records for monitored individuals represents the size of the DOE workforce monitored for radiation dose. The number of records for monitored individuals is not the same as the workforce, as it could include the same individual more than once. The number represents the sum of all records for monitored individuals, including all DOE employees, contractors, and subcontractors, as well as members of the public in controlled areas that are monitored for exposure to radiation. Individuals that have more than one record due to being monitored at more than one site comprise less than $3 \%$ of the monitored workers; therefore, the multiple counting has minimal impact on the totals and averages presented in this report (see section 3.5). This is because of the conservative practice at some DOE facilities of providing radiation dose monitoring to individuals for reasons other than the potential for exposure to radiation and/or radioactive materials exceeding the monitoring thresholds specified in 10 C.F.R. 835.402. Many individuals are monitored for reasons such as security, administrative convenience, and legal liability. Some sites offer monitoring for any individual who requests monitoring, independent of the potential for exposure. For this reason, the number of records for workers who receive a measurable dose best represents the exposed workforce.

\subsubsection{Number of Records for Individuals with Measurable Dose}

DOE uses the number of individuals receiving a measurable dose to represent the exposed workforce size. The number of individuals with a measurable dose includes all individuals that received a reported detectable dose.

Over the past 5-year period, $99.99 \%$ of the individuals receiving measurable TED have received doses below the 2 rems $(20 \mathrm{mSv})$ TED ACL, which is well below the DOE regulatory limit of 5 rems $(50 \mathrm{mSv})$ TED.

Exhibits 3-1 $a$ and 3-1b show the number of DOE and contractor workers, the total number of workers

\section{Exhibit 3-1a:}

Monitoring of the DOE Workforce, 2008-2012.

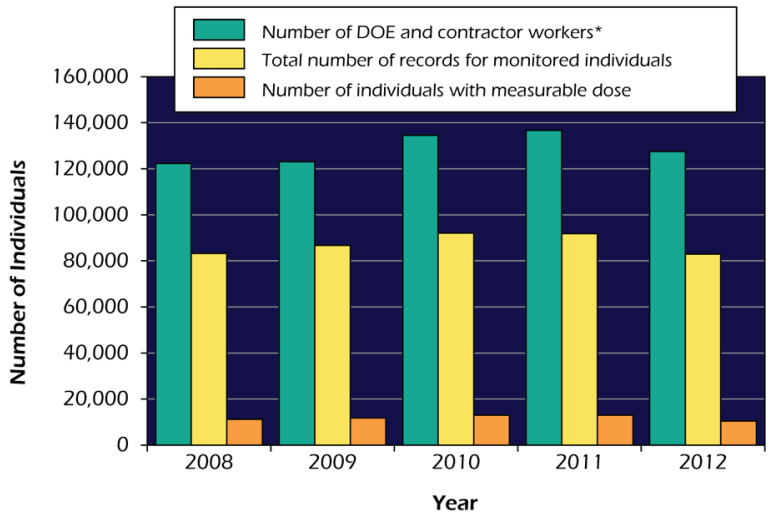

* The number of DOE and contractor workers was determined from the total annual work hours at DOE [9] converted to fulltime equivalents.

For 2012, 65\% of the DOE workforce was monitored for radiation dose, and $13 \%$ of monitored individuals received a measurable dose. 


\section{Exhibit 3-16:}

Monitoring of the DOE Workforce, 2008-2012.

\begin{tabular}{|c|c|c|c|c|c|}
\hline Year & $\begin{array}{c}\text { DOE \& } \\
\text { Contractor } \\
\text { Workforce }\end{array}$ & $\begin{array}{l}\text { Number of } \\
\text { Workers } \\
\text { Monitored }\end{array}$ & $\begin{array}{l}\text { Percent of } \\
\text { Workers } \\
\text { Monitored* }\end{array}$ & $\begin{array}{c}\text { Number } \\
\text { Monitored } \\
\text { w/Measurable } \\
\text { Dose }\end{array}$ & $\begin{array}{c}\text { Percent } \\
\text { Monitored } \\
\text { w/Measurable } \\
\text { Dose* }\end{array}$ \\
\hline 2008 & 122,287 & 83,235 & $68 \% \nabla$ & 11,297 & $14 \% \triangle$ \\
\hline 2009 & 123,065 & 86,703 & $70 \% \triangle$ & 11,758 & $14 \%$ \\
\hline 2010 & 134,621 & 92,089 & $68 \% \nabla$ & 13,047 & $14 \%$ \\
\hline 2011 & 136,701 & 91,864 & $67 \% \nabla$ & 12,972 & $14 \%$ \\
\hline 2012 & 127,573 & 82,994 & $65 \% \nabla$ & 10,458 & $13 \% \nabla$ \\
\hline 5-Year Average & 128,849 & 87,377 & $68 \%$ & 11,906 & $14 \%$ \\
\hline
\end{tabular}

* Up arrows indicate an increase from the previous year's value. Down arrows indicate a decrease from the previous year's value.

monitored for radiation dose, the number of individuals with a measurable dose, and the relative percentages for the past 5 years.

Over the past 5 years, the percentage of individuals monitored for radiation exposure has remained within $5 \%$ of the 5 -year average; the percentage of monitored individuals receiving any measurable radiation dose each year has been within $8 \%$ of the 5 -year average.

Twenty of the reporting sites experienced decreases in the number of workers with a measurable TED from 2011 to 2012. The largest decrease in total number of workers with a measurable TED occurred at the Idaho Site with a decrease of 1,143 workers. Twelve of the reporting sites experienced increases in the number of workers with a measurable TED from 2011 to 2012. The largest increase in the number of workers receiving a measurable TED occurred at the Portsmouth Gaseous Diffusion Plant. A discussion of activities at the highest dose facilities is included in Section 3.4.3.

\subsubsection{Collective Dose}

The collective dose is the sum of the dose received by all individuals with a measurable dose and is measured in units of person-rem (mSv). As used in this report, the collective dose is a measure of the overall occupational radiation exposure at DOE facilities and includes the dose to all DOE employees, contractors, and subcontractors, as well as members of the public in controlled areas that are monitored for exposure to radiation. DOE monitors the collective dose as one measure of the overall performance of radiation protection programs to keep individual exposures and collective exposures ALARA.
As shown in Exhibit 32 , the collective TED decreased at DOE $17.1 \%$ from 866.9 person-rems (8,669 person-mSv) in 2011 to 718.5 person-rems (7,185 person-mSv) in 2012.

The internal dose is based on the 50-year Committed Effective Dose (CED) methodology. Under this methodology, the cumulative dose received from the intake of radioactive material over the next 50 years is assigned to the individual as a one-time dose in the year of intake. The internal dose component of the collective TED decreased by 7\% from 53.4 person-rems (534 person-mSv) in 2011 to 49.8 person-rems (498 person$\mathrm{mSv}$ ) in 2012 . The reduction in isotope processing at ORNL, a 3-month curtailment period at UMTRA and the completion of high dose-rate jobs at the Idaho Cleanup Project contributed to the decrease in collective CED in 2012. The collective photon dose decreased by $23 \%$ from 669.6 person-rems (6,696 person-mSv) in 2011 to 517.8 person-rems (5,178 person-mSv) in 2012.

The neutron component of the TED increased by $5 \%$ from 143.9 person-rems (1,439 person-mSv) in 2011 to 150.9 person-rems (1,509 person-mSv) in 2012. This is due primarily to a $23 \%$ increase in neutron dose at LANL. The primary contributor to increased dose at LANL was additional work with $\mathrm{Pu}-238$, producing general purpose heat sources in radioisotope thermoelectric generators. In addition, Brookhaven National Laboratory (BNL) reported an increase in neutron dose, due to an increase in neutron calibration work for the Department of Homeland Security (DHS).

Twenty of the DOE sites reported decreases in the collective TED from the 2011 values, while 12 of the DOE sites reported increases. The 5 sites that contributed most (81\%) of the DOE collective TED in 2012 were (in 
Exhibit 3-2:

Components of TED, 2008-2012.

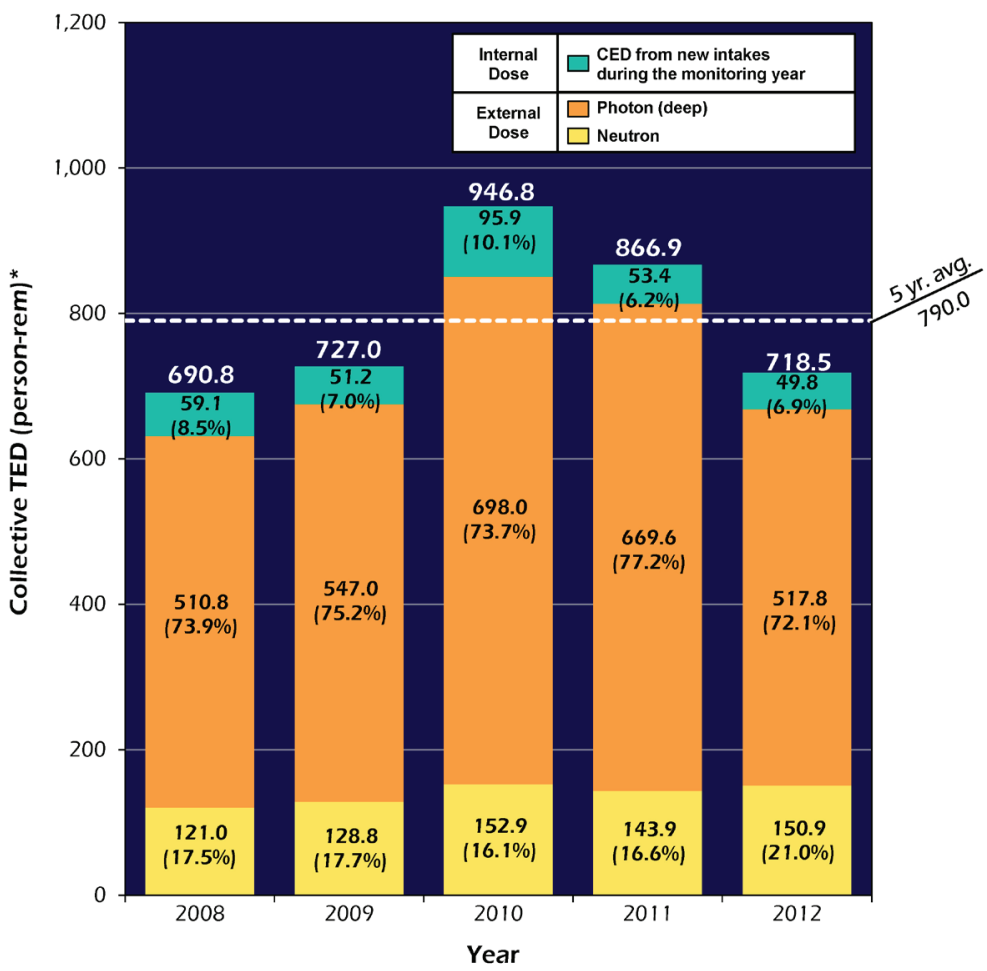

The collective TED decreased by $17 \%$ at DOE from 2011 to 2012.

The collective internal dose decreased by $7 \%$ from 2011 to 2012.

Neutron dose increased by $5 \%$ from 2011 to 2012.

Photon dose decreased by 23\% from 2011 to 2012.

Effective Dose from photons - the component of external dose from gamma or X-ray electromagnetic radiation (also includes energetic betas)

Effective dose from neutrons-the component of external dose from neutrons ejected from the nucleus of an atom during nuclear reactions

Internal dose-radiation dose resulting from radioactive material taken into the body

* The percentages in parentheses represent the percentage of each dose component to the collective TED.

descending order of collective TED): Savannah River Site (SRS) - 20\% (including Savannah River Nuclear Solutions [SRNS] and Savannah River Remediation [SRR]); Los Alamos National Laboratory (LANL) - 19\%; Oak Ridge - 19\% (including East Tennessee Technology Park [ETTP], Y-12 National Security Complex [Y-12], Oak Ridge National Laboratory [ORNL], and Oak Ridge Institute for Science and Education [ORISE]; Hanford - 14\% (including the Hanford Site, Pacific Northwest National Laboratory [PNNL], and the Office of River Protection [ORP]); and Idaho Site - 9\% (including INL, Idaho Cleanup Project [ICP] and AMWTP).

Three of these sites reported decreases in the collective TED in 2012 compared with 2011. The three sites in descending order of the percent decrease in collective TED are Idaho (53\%), Hanford (31\%), and SRS (3\%).

\subsubsection{Average Measurable Dose}

The average measurable dose to DOE workers, a key radiation dose indicator, is calculated by dividing the collective dose (in this case, TED) by the number of individuals with a measurable dose for each dose type.
The average measurable TED is shown in Exhibit 3-3.

The average measurable TED increased by $3 \%$ from $0.067 \mathrm{rem}(0.67 \mathrm{mSv})$ in 2011 to $0.069 \mathrm{rem}(0.69 \mathrm{mSv})$ in

| Exhibit 3-3:

Average Measurable TED, 2008-2012.

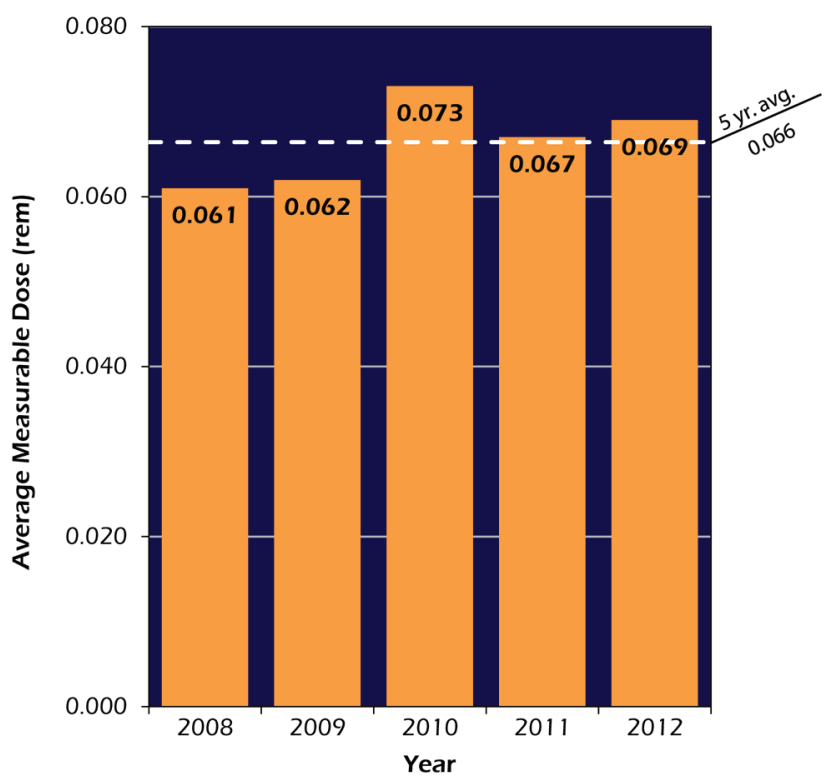


2012, slightly higher than the 5-year average. While the collective dose and average measurable dose serve as measures of the magnitude of the dose accrued by DOE workers, they do not depict the distribution of doses among the worker population.

\subsubsection{Dose Distribution}

Exposure data are commonly analyzed in terms of dose intervals to depict the dose distribution among the worker population. Exhibit 3-4 shows the number of individuals in each of 11 different dose ranges. The number of individuals receiving doses above 0.100 rem $(1 \mathrm{mSv})$ is included to show the number of individuals with doses above the monitoring threshold specified in 10 C.F.R. 835.402(a) and (c) [6].

Exhibit 3-4 shows that the dose distribution for 2012 was slightly lower in every range but the 1 to 2 rems range compared with the 2011 data. Exhibit 3-5 presents the dose distribution in terms of the percentage of individuals with measurable TED in each range. The percentages shown in this manner assist in revealing changes in the distribution from year to year. It shows that the values remained relatively constant, which is consistent with the overall increase in the average measurable TED during 2012 as a result of the decreased activities funded under ARRA and continuing D\&D.

Exhibit 3-4:

Distribution of TED by Dose Range, 2008-2012.

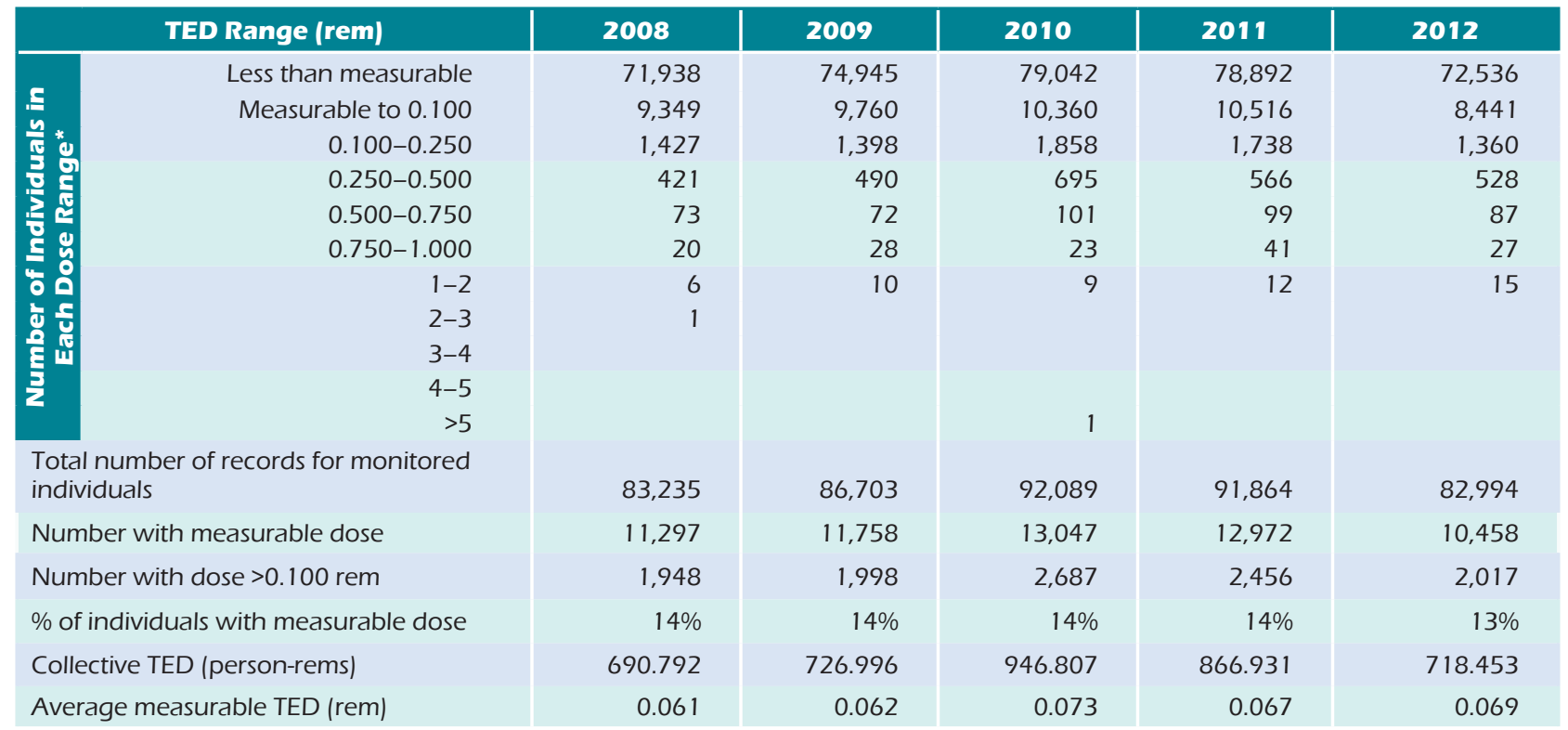

* Individuals with doses equal to the dose value separating the dose ranges are included in the next higher dose range.

Exhibit 3-5:

Percentage of Individuals with Measurable TED by Dose Range, 2008 - 2012.

\begin{tabular}{|c|c|c|c|c|c|c|}
\hline \multicolumn{2}{|c|}{ TED Range (rem) } & 2008 & 2009 & 2010 & 2011 & 2012 \\
\hline & Measurable <0.100 & $82.8 \%$ & $83.0 \%$ & $79.4 \%$ & $81.1 \%$ & $80.7 \%$ \\
\hline 룽 요 & $0.100-0.250$ & $12.6 \%$ & $11.9 \%$ & $14.2 \%$ & $13.4 \%$ & $13.0 \%$ \\
\hline 20 & $0.250-0.500$ & $3.7 \%$ & $4.2 \%$ & $5.3 \%$ & $4.4 \%$ & $5.0 \%$ \\
\hline$\frac{2}{4}$ & $0.500-0.750$ & $0.6 \%$ & $0.6 \%$ & $0.8 \%$ & $0.8 \%$ & $0.8 \%$ \\
\hline U & $0.750-1.000$ & $0.2 \%$ & $0.2 \%$ & $0.2 \%$ & $0.3 \%$ & $0.3 \%$ \\
\hline 폴 & $1-2$ & $0.1 \%$ & $0.1 \%$ & $0.1 \%$ & $0.1 \%$ & $0.1 \%$ \\
\hline 엉 & $2-3$ & $0.01 \%$ & $0.0 \%$ & $0.0 \%$ & $0.0 \%$ & $0.0 \%$ \\
\hline$\stackrel{2}{a}>$ & $>3$ & $0.0 \%$ & $0.0 \%$ & $0.01 \%$ & $0.0 \%$ & $0.0 \%$ \\
\hline
\end{tabular}

* Individuals with doses equal to the dose value separating the dose ranges are included in the next higher dose range. 


\subsection{Analysis of Individual Dose Data}

The previous analysis is based on aggregate data for DOE. From an individual worker perspective, as well as a regulatory perspective, it is important to closely examine the doses received by individuals in the elevated dose ranges to thoroughly understand the circumstances leading to these doses in the workplace and to better manage and avoid these doses in the future. The following sections focus on doses received by individuals that were in excess of the DOE limit (5 rems [50 mSv] TED) and the DOE recommended ACL (2 rems [20 mSv] TED).

\subsubsection{Doses in Excess of DOE Limit}

Exhibit 3-6 shows the number of doses in excess of the TED regulatory limit (5 rems [50 mSv]) from 2008 through 2012.

No individual was reported to have exceeded 5 rems in 2012.

\subsubsection{Doses in Excess of Administrative Control Level}

The Radiological Control Standard (RCS) [10] recommends a 2 rems $(20 \mathrm{mSv})$ ACL for TED per year per person for all DOE activities. Prior to allowing an individual to exceed this level, approval from the appropriate Secretarial officer or designee should be received. The RCS recommends that each DOE site establish its own more restrictive ACL that would require contractor management approval to be exceeded.

No individual exceeded 2 rems in 2012.

Exhibit 3-6:

Number of Individuals Exceeding 2 rems ACL and the 5 rems Annual Limit, 2008-2012.

\begin{tabular}{|c|c|c|}
\hline Year & $>2$ rems & $>5$ rems \\
\hline 2008 & 1 & \\
2009 & & \\
2010 & & 1 \\
2011 & & \\
2012 & & \\
\hline
\end{tabular}

In 2012, no individual received a TED in excess of 2 rems (20 mSv).
As shown in Exhibit 3-6, two individuals have exceeded the 2 rems $(20 \mathrm{mSv})$ ACL in the past 5 years. One individual also exceeded the 5 rems $(50 \mathrm{mSv})$ annual limit.

\subsubsection{Intakes of Radioactive Material}

As shown in Exhibit 3-7, some of the highest doses to individuals have been the result of intakes of radioactive material. For this reason, DOE tracks the number of intakes as a performance measure in this report. DOE emphasizes the importance of taking measures to avoid intakes and maintain doses ALARA.

Exhibit 3-8 shows the number of internal depositions of radioactive material (an indicator of worker intakes), collective CED, and average measurable CED for 2008 to 2012. The number of internal depositions decreased by $13 \%$ from 1,549 in 2011 to 1,354 in 2012, while the collective CED decreased by $7 \%$. The average measurable CED increased by $9 \%$ from 0.034 rem (0.34 $\mathrm{mSv})$ in 2011 to $0.037 \mathrm{rem}(0.37 \mathrm{mSv})$ in 2012 .

Ninety-three percent of the collective CED in 2012 was from uranium intakes at Y-12 during the operation and management of Enriched Uranium Operations facilities at the site. Compared with external dose, relatively few workers at DOE receive measurable internal dose, so larger fluctuations may occur from year to year in the number of workers and collective CED, than for other components of TED.

Exhibit 3-9 shows the distribution of the internal dose from 2008 to 2012. The total number of individuals with intakes in each dose range is the sum of all records of intake in the subject dose range. Individuals with multiple intakes during the year may be counted more than once. Doses below 0.020 rem $(0.20 \mathrm{mSv})$ are shown as a separate dose range, to show the large number of doses in this low dose range. The decrease in the number of individuals with measurable CED in 2012 is primarily due to the limited operations at Y-12, which lowered the number of minimal intakes.

The internal dose records indicate that the majority of the intakes result in very low doses. In $2012,54 \%$ of the internal dose records were for doses below $0.020 \mathrm{rem}$ $(0.20 \mathrm{mSv})$. Over the 5-year period, internal doses from intakes accounted for $8 \%$ of the collective TED, and only $10 \%$ of the individuals who received internal doses were above the monitoring threshold ( 0.1 person-rem [ 1 $\mathrm{mSv}$ ]) specified in 10 C.F.R. 835.402(c) [6]. 
Exhibit 3-7:

Dose in Excess of DOE Administrative Control Levels, 2008-2012.

\begin{tabular}{|c|c|c|c|c|c|c|c|}
\hline Year & $\begin{array}{c}\text { Total Effective } \\
\text { Dose (TED) } \\
\text { (External + } \\
\text { Internal Dose) } \\
\text { (rem) }\end{array}$ & $\begin{array}{l}\text { Effective Dose } \\
\text { (ED) from } \\
\text { External } \\
\text { Sources } \\
\text { (rem) }\end{array}$ & $\begin{array}{l}\text { Committed } \\
\text { Effective Dose } \\
\text { (CED) from } \\
\text { Intakes } \\
\text { (rem) }\end{array}$ & $\begin{array}{c}\text { Committed } \\
\text { Equivalent } \\
\text { Dose (CEqD) } \\
\text { from Intakes } \\
\text { (rem) }\end{array}$ & $\begin{array}{l}\text { Intake } \\
\text { Nuclides }\end{array}$ & $\begin{array}{l}\text { Facility } \\
\text { Types }\end{array}$ & Site \\
\hline 2008 & 2.106 & 0.286 & 1.820 & 60.325 & Pu-238, Pu-239 & TA-55 Facility & LANL \\
\hline 2009 & & & & None reported & & & \\
\hline 2010 & 31.618 & 0.029 & 31.589 & $1,043.190$ & Pu-238 & $\begin{array}{l}\text { Transuranic (TRU) Waste } \\
\text { Remediation Facility }\end{array}$ & SRS \\
\hline 2011 & & & & None reported & & & \\
\hline 2012 & & & & None reported & & & \\
\hline
\end{tabular}

Exhibit 3-8:

Number of Internal Depositions, Collective CED, and Average Measurable CED, 2008-2012.

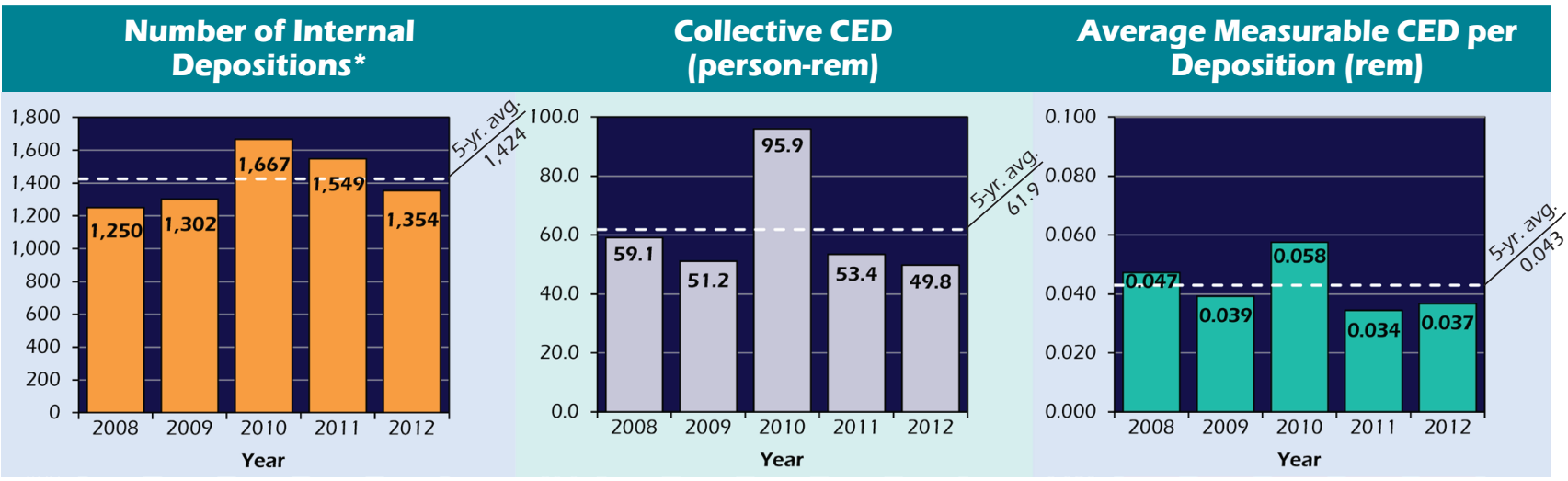

* The number of internal depositions represents the number of internal dose records with positive results reported for each individual. Individuals may have multiple intakes in a year and, therefore, may be counted more than once.

Exhibit 3-9:

Internal Dose Distribution from Intakes, 2008-2012.

\begin{tabular}{|c|c|c|c|c|c|c|c|c|c|c|c|c|c|}
\hline \multirow[b]{2}{*}{ Year } & \multicolumn{11}{|c|}{ Number of Individuals with CED in the Ranges (rem)* } & \multirow{2}{*}{$\begin{array}{c}\text { Total } \\
\text { No. of } \\
\text { Indiv.** }\end{array}$} & \multirow{2}{*}{$\begin{array}{c}\text { Total } \\
\text { Collective } \\
\text { CED } \\
\text { Iperson-rem }\end{array}$} \\
\hline & $\begin{array}{l}\text { Meas. } \\
<0.020\end{array}$ & $\begin{array}{l}0.020 \\
0.100\end{array}$ & $\begin{array}{l}0.100- \\
0.250\end{array}$ & $\begin{array}{l}0.250- \\
0.500\end{array}$ & $\begin{array}{l}0.500- \\
0.750\end{array}$ & $\begin{array}{c}0.750 \\
1.000\end{array}$ & $\begin{array}{l}1.0- \\
2.0\end{array}$ & $\begin{array}{l}2.0- \\
3.0\end{array}$ & $\begin{array}{l}3.0- \\
4.0\end{array}$ & $\begin{array}{l}4.0- \\
5.0\end{array}$ & $>5.0$ & & \\
\hline 2008 & 616 & 471 & 133 & 25 & 2 & 2 & 1 & & & & & 1,250 & 59.062 \\
\hline 2009 & 707 & 456 & 118 & 16 & 4 & 1 & & & & & & 1,302 & 51.162 \\
\hline 2010 & 895 & 612 & 137 & 19 & 1 & 1 & 1 & & & & 1 & 1,667 & 95.928 \\
\hline 2011 & 889 & 536 & 109 & 12 & 1 & & 2 & & & & & 1,549 & 53.389 \\
\hline 2012 & 734 & 478 & 125 & 16 & 1 & & & & & & & 1,354 & 49.786 \\
\hline
\end{tabular}

* Individuals with doses equal to the dose value separating the dose ranges are included in the next higher dose range.

** Individuals may have multiple intakes in a year and, therefore, may be counted more than once. 


\subsubsection{Bioassay and Intake Summary Information}

For the monitoring year 2012, bioassay and intake summary information was required to be reported under the REMS Reporting Guide [8]. During the past 3 years, urinalysis has been reported as the most common method of bioassay measurement used to determine internal doses to the individuals. Exhibit 3-10 shows the breakdown of bioassay measurements by measurement type and number of measurements. The measurements reported under "in vivo" include direct measurements of the radioactive material in the body of the monitored person. Examples of in vivo measurements include whole body counts and lung or thyroid counts. The measurements reported in "Other" are for air samples taken in the workplace that are used to calculate the amount of airborne radioactive material taken into the body and the resultant internal dose. Note that the numbers shown are based on the number of measurements taken and not the number of individuals monitored. Individuals may have measurements taken more than once during the year.

Fifty-four percent of the urinalysis measurements in 2012 were performed at three sites: Y-12, LANL, and SRS. The majority of the bioassay measurements reported as "Other" were from air sampling and account for $30 \%$ of the total measurements. Over $46 \%$ of the in vivo measurements were from Hanford. Hanford also performs the largest number of bioassay measurements overall, comprising $26 \%$ of the total measurements taken. Of the 5 largest contributing sites, ORNL had the largest percentage increase (38\%) in the number of urinalysis measurements in 2012 and Pantex reported the only increase (21\%) in the number of "Other" measurements.

Exhibit 3-10:

Bioassay and Air Sampling Measurements, 2010-2012.

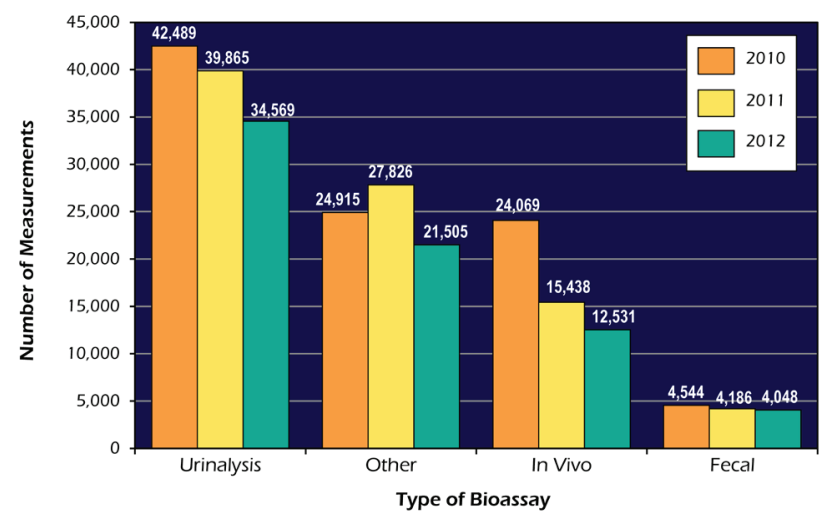

Exhibit 3-11 shows the breakdown of the collective CED by radionuclide for 2012. Uranium-234 accounts for the largest percentage of the collective CED, with over 93\% of this dose accrued at Y-12.

\section{Exhibit 3-11:}

Collective CED by Radionuclide, 2012.

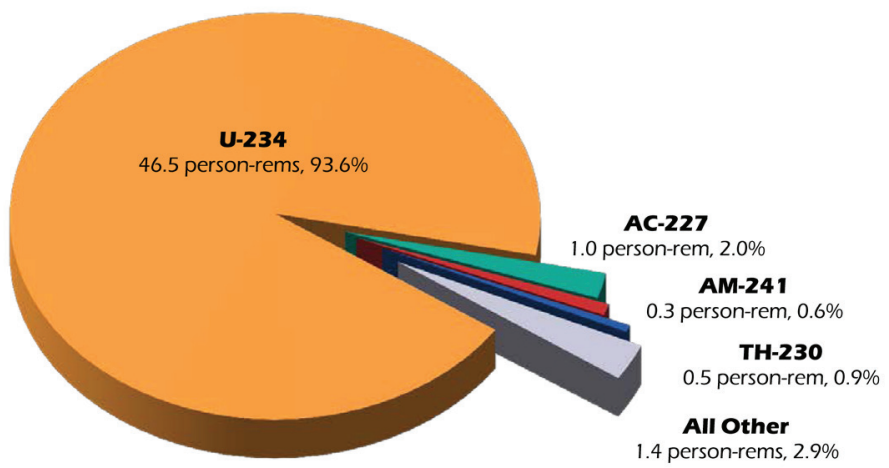

\subsection{Analysis of Site Data}

\subsubsection{Collective TED by Site and Other Facilities}

The collective TED for 2010 through 2012 for the major DOE sites and operations/field offices are shown graphically in Exhibit 3-12. A list of the collective TED and number of individuals with measurable TED by DOE sites is shown in Exhibit 3-13. The collective TED decreased $17.1 \%$ from 867 person-rems (8,670 person$\mathrm{mSv}$ ) in 2011 to 718 person-rems (7,180 person-mSv) in 2012, with Savannah River (including SRNS and SRR), LANL, Oak Ridge sites (including ETTP, Y-12, ORNL, and ORISE), Hanford (including the Hanford Site, PNNL, and the ORP), and Idaho Site (including INL, ICP and AMWTP) contributing $81 \%$ of the total DOE collective TED.

\subsubsection{Changes by Site from 2011 to 2012}

Exhibit 3-14 shows the collective TED, the number with a measurable TED, the average measurable TED, and the percentage of the collective TED delivered above 0.500 rem by site for 2012, as well as the percentage change in these values from the previous year. Some of the largest percentage changes occurred at relatively small facilities where conditions may fluctuate from year to year. The changes that had the most impact in the overall values at DOE occurred at sites with a relatively large collective TED in addition to a large percentage change, such as Savannah River in 2012. 


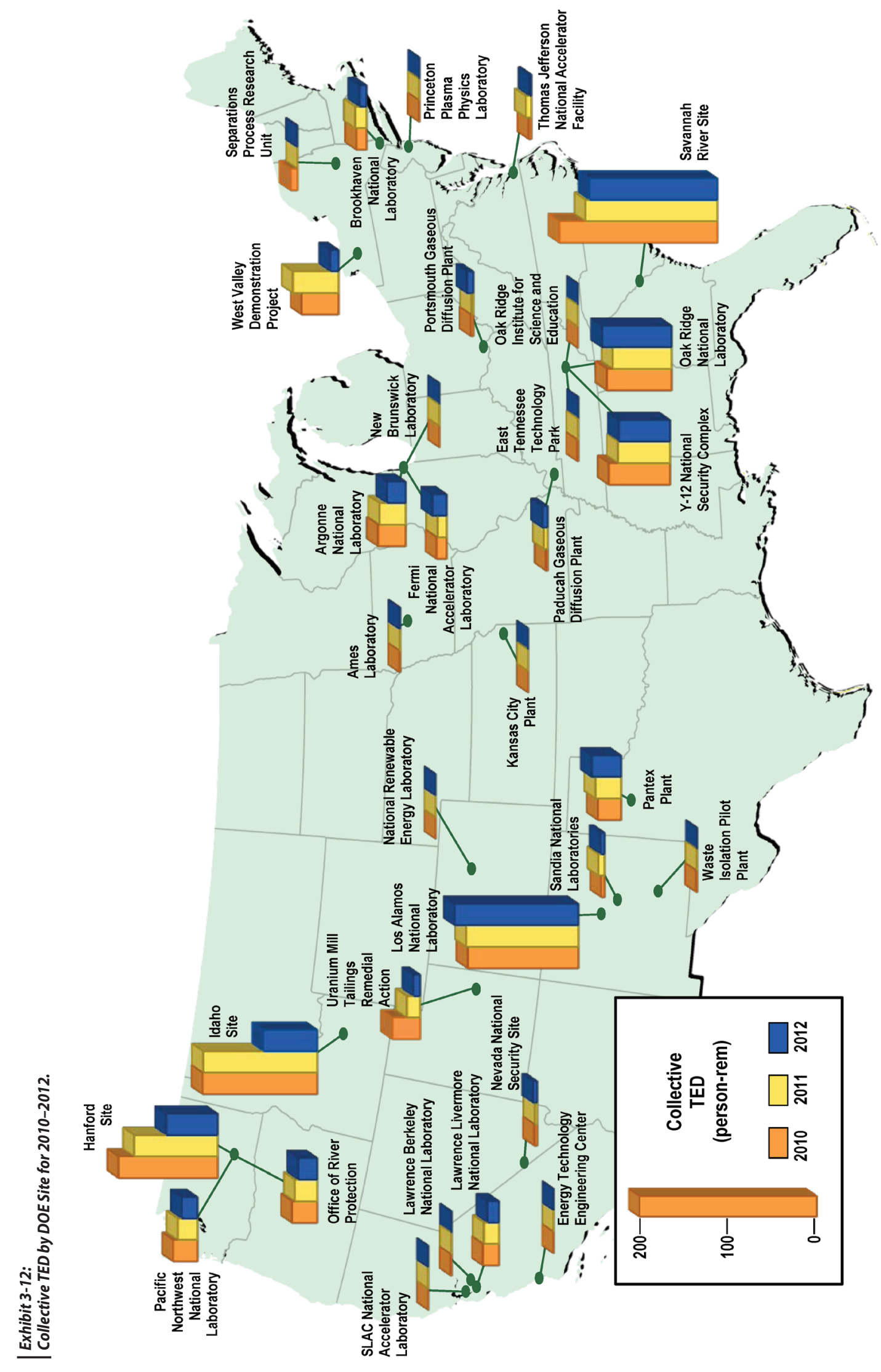


Exhibit 3-13:

Collective TED and Number of Individuals with Measurable TED by DOE Site, 2010-2012.

\begin{tabular}{|c|c|c|c|c|c|c|}
\hline \multirow[b]{2}{*}{ Site } & \multicolumn{2}{|c|}{2010} & \multicolumn{2}{|c|}{2011} & \multicolumn{2}{|c|}{2012} \\
\hline & $\begin{array}{l}\text { Collective } \\
\text { TED } \\
\text { (person- } \\
\text { rem) }\end{array}$ & $\begin{array}{c}\text { Number } \\
\text { with } \\
\text { Meas. } \\
\text { TED }\end{array}$ & $\begin{array}{l}\text { Collective } \\
\text { TED } \\
\text { (person- } \\
\text { rem) }\end{array}$ & $\begin{array}{c}\text { Number } \\
\text { with } \\
\text { Meas. } \\
\text { TED }\end{array}$ & $\begin{array}{c}\text { Collective } \\
\text { TED } \\
\text { (person- } \\
\text { rem) }\end{array}$ & $\begin{array}{c}\text { Number } \\
\text { with } \\
\text { Meas. } \\
\text { TED }\end{array}$ \\
\hline Ames Laboratory & 0.907 & 32 & 0.762 & 29 & 0.820 & 25 \\
\hline Argonne National Laboratory & 31.170 & 177 & 29.552 & 177 & 21.146 & 121 \\
\hline Brookhaven National Laboratory & 11.529 & 214 & 12.822 & 172 & 7.981 & 171 \\
\hline Energy Technology Engineering Center & 0.292 & 54 & 0.139 & 47 & 0.226 & 54 \\
\hline Fermi National Accelerator Laboratory & 11.220 & 169 & 10.090 & 155 & 15.980 & 207 \\
\hline \multicolumn{7}{|l|}{ Hanford: } \\
\hline Hanford Site & 112.522 & 1,673 & 94.691 & 1,479 & 58.349 & 926 \\
\hline Office of River Protection & 28.522 & 535 & 25.308 & 496 & 21.528 & 413 \\
\hline Pacific Northwest National Laboratory & 27.500 & 280 & 22.336 & 257 & 17.779 & 240 \\
\hline Idaho Site & 130.278 & 1,890 & 129.728 & 2,398 & 61.275 & 1,255 \\
\hline Kansas City Plant & 0.046 & 10 & 0.049 & 2 & 0.021 & 6 \\
\hline Lawrence Berkeley National Laboratory & 1.097 & 16 & 0.759 & 13 & 0.497 & 10 \\
\hline Lawrence Livermore National Laboratory & 18.214 & 144 & 16.979 & 116 & 13.037 & 131 \\
\hline Los Alamos National Laboratory & 125.389 & 1,335 & 127.056 & 1,459 & 140.148 & 1,438 \\
\hline National Renewable Energy Laboratory & 0.022 & 3 & 0.017 & 5 & 0.020 & 4 \\
\hline Nevada National Security Site & 3.288 & 84 & 2.743 & 78 & 4.284 & 100 \\
\hline New Brunswick Laboratory & 0.037 & 3 & 0.165 & 8 & 0.039 & 2 \\
\hline \multicolumn{7}{|l|}{ Oak Ridge: } \\
\hline East Tennessee Technology Park & 1.187 & 43 & 0.830 & 39 & 0.306 & 14 \\
\hline Oak Ridge Institute for Science and Education & 0.114 & 56 & 0.211 & 82 & 0.124 & 23 \\
\hline Oak Ridge National Laboratory & 73.481 & 731 & 66.800 & 730 & 78.792 & 764 \\
\hline Y-12 National Security Complex & 69.516 & 1,635 & 59.055 & 1,537 & 58.245 & 1,412 \\
\hline Paducah Gaseous Diffusion Plant & 1.884 & 90 & 4.038 & 78 & 5.984 & 113 \\
\hline Pantex Plant & 26.131 & 303 & 28.947 & 311 & 33.118 & 339 \\
\hline Portsmouth Gaseous Diffusion Plant & 2.960 & 63 & 2.279 & 47 & 7.092 & 135 \\
\hline Princeton Plasma Physics Laboratory & 0.663 & 79 & 0.401 & 53 & 0.334 & 43 \\
\hline Sandia National Laboratories & 3.606 & 83 & 6.913 & 126 & 4.315 & 122 \\
\hline Savannah River Site & 179.572 & 2,587 & 149.967 & 2,512 & 145.443 & 2,044 \\
\hline Separations Process Research Unit & 7.850 & 74 & 0.179 & 13 & 0.584 & 23 \\
\hline SLAC National Accelerator Laboratory & 0.053 & 4 & 0.236 & 10 & 0.315 & 15 \\
\hline Thomas Jefferson National Accelerator Facility & 3.111 & 67 & 6.245 & 57 & 1.963 & 85 \\
\hline Uranium Mill Tailings Remedial Action Project & 31.497 & 237 & 15.000 & 191 & 7.673 & 87 \\
\hline Waste Isolation Pilot Plant & 1.199 & 62 & 0.476 & 25 & 0.298 & 18 \\
\hline West Valley Demonstration Project & 41.873 & 308 & 51.662 & 247 & 9.312 & 86 \\
\hline Service Center Personnel ${ }^{\star}$ & 0.077 & 6 & 0.496 & 23 & 1.425 & 32 \\
\hline Totals & 946.807 & 13,047 & 866.931 & 12,972 & 718.453 & 10,458 \\
\hline
\end{tabular}

Note: Bold values indicate the greatest value in each column.

* Includes personnel at NNSA Albuquerque complex and Oak Ridge in addition to several smaller facilities not associated with a DOE site. 
Exhibit 3-14:

Site Dose Data, 2012.

\begin{tabular}{|c|c|c|c|c|c|c|c|c|}
\hline \multirow[b]{2}{*}{ Site } & \multicolumn{8}{|c|}{2012} \\
\hline & $\begin{array}{c}\text { Collective } \\
\text { TED } \\
\text { (person- } \\
\text { rem) }\end{array}$ & $\begin{array}{c}\text { Percent } \\
\text { Change } \\
\text { from } \\
2011\end{array}$ & $\begin{array}{c}\text { Number } \\
\text { with } \\
\text { Meas. } \\
\text { Dose }\end{array}$ & $\begin{array}{c}\text { Percent } \\
\text { Change } \\
\text { from } \\
2011\end{array}$ & $\begin{array}{l}\text { Avg. } \\
\text { Meas. } \\
\text { TED } \\
\text { (rem) }\end{array}$ & $\begin{array}{c}\text { Percent } \\
\text { Change } \\
\text { from } \\
2011\end{array}$ & $\begin{array}{l}\text { Percentage } \\
\text { of Coll. } \\
\text { TED above } \\
0.500 \text { rem }\end{array}$ & $\begin{array}{c}\text { Percent } \\
\text { Change } \\
\text { from } \\
2011\end{array}$ \\
\hline Ames Laboratory & 0.820 & $\diamond$ & 25 & $\diamond$ & 0.033 & $\diamond$ & & \\
\hline Argonne National Laboratory & 21.146 & $-28 \% \nabla$ & 121 & $-32 \% \nabla$ & 0.175 & $5 \% \Delta$ & $52 \%$ & $7 \% \Delta$ \\
\hline Brookhaven National Laboratory & 7.981 & $-38 \% \nabla$ & 171 & $-1 \% \nabla$ & 0.047 & $-37 \% \nabla$ & $7 \%$ & $-71 \% \nabla$ \\
\hline Energy Technology Engineering Center & 0.226 & $\diamond$ & 54 & $\diamond$ & 0.004 & $\diamond$ & & \\
\hline Fermi National Accelerator Laboratory & 15.980 & $58 \% \triangle$ & 207 & $34 \% \Delta$ & 0.077 & $19 \% \Delta$ & $4 \%$ & $100 \% \Delta$ \\
\hline \multicolumn{9}{|l|}{ Hanford: } \\
\hline Hanford Site & 58.349 & $-38 \% \nabla$ & 926 & $-37 \% \nabla$ & 0.063 & $-2 \% \nabla$ & $7 \%$ & $100 \% \Delta$ \\
\hline Office of River Protection & 21.528 & $-15 \% \nabla$ & 413 & $-17 \% \nabla$ & 0.052 & $2 \% \Delta$ & & \\
\hline Pacific Northwest National Laboratory & 17.779 & $-20 \% \nabla$ & 240 & $-7 \% \mathbf{\nabla}$ & 0.074 & $-15 \% \nabla$ & $16 \%$ & $-28 \% \nabla$ \\
\hline Idaho Site & 61.275 & $-53 \% \nabla$ & 1,255 & $-48 \% \nabla$ & 0.049 & $-10 \% \nabla$ & & \\
\hline Kansas City Plant & 0.021 & $\diamond$ & 6 & $\diamond$ & 0.004 & $\diamond$ & & \\
\hline Lawrence Berkeley National Laboratory & 0.497 & $\diamond$ & 10 & $\diamond$ & 0.050 & $\diamond$ & & \\
\hline Lawrence Livermore National Laboratory & 13.037 & $-23 \% \nabla$ & 131 & $13 \% \Delta$ & 0.100 & $-32 \% \nabla$ & $22 \%$ & $-58 \% \nabla$ \\
\hline Los Alamos National Laboratory & 140.148 & $10 \% \Delta$ & 1,438 & $-1 \% \nabla$ & 0.097 & $12 \% \Delta$ & $34 \%$ & $57 \% \Delta$ \\
\hline National Renewable Energy Laboratory & 0.020 & $\diamond$ & 4 & $\diamond$ & 0.005 & $\diamond$ & & \\
\hline Nevada National Security Site & 4.284 & $56 \% \triangle$ & 100 & $28 \% \Delta$ & 0.043 & $22 \%$ & & \\
\hline New Brunswick Laboratory & 0.039 & $\diamond$ & 2 & $\diamond$ & 0.020 & $\diamond$ & & \\
\hline \multicolumn{9}{|l|}{ Oak Ridge: } \\
\hline East Tennessee Technology Park & 0.306 & $\diamond$ & 14 & $\diamond$ & 0.022 & $\diamond$ & & \\
\hline Oak Ridge Institute for Science and Education & 0.124 & $\diamond$ & 23 & $\diamond$ & 0.005 & $\diamond$ & & \\
\hline Oak Ridge National Laboratory & 78.792 & $18 \% \Delta$ & 764 & $5 \% \triangle$ & 0.103 & $13 \% \Delta$ & $15 \%$ & $114 \%$ \\
\hline Y-12 National Security Complex & 58.245 & $-1 \% \nabla$ & 1,412 & $-8 \% \nabla$ & 0.041 & $7 \% \Delta$ & $1 \%$ & $-2 \% \nabla$ \\
\hline Paducah Gaseous Diffusion Plant & 5.984 & $48 \% \triangle$ & 113 & $45 \% \Delta$ & 0.053 & $2 \% \Delta$ & & \\
\hline Pantex Plant & 33.118 & $14 \% \triangle$ & 339 & $9 \% \Delta$ & 0.098 & $5 \% \triangle$ & $9 \%$ & $32 \% \Delta$ \\
\hline Portsmouth Gaseous Diffusion Plant & 7.092 & $211 \% \Delta$ & 135 & $187 \%$ & 0.053 & $8 \% \Delta$ & & \\
\hline Princeton Plasma Physics Laboratory & 0.334 & $\diamond$ & 43 & $\diamond$ & 0.008 & $\diamond$ & & \\
\hline Sandia National Laboratories & 4.315 & $-38 \% \nabla$ & 122 & $-3 \% \nabla$ & 0.035 & $-36 \% \nabla$ & & \\
\hline Savannah River Site & 145.443 & $-3 \% \nabla$ & 2,044 & $-19 \% \nabla$ & 0.071 & $19 \%$ & $5 \%$ & $-11 \% \nabla$ \\
\hline Separations Process Research Unit & 0.584 & $\diamond$ & 23 & $\diamond$ & 0.025 & $\diamond$ & & \\
\hline SLAC National Accelerator Laboratory & 0.315 & $\diamond$ & 15 & $\diamond$ & 0.021 & $\diamond$ & & \\
\hline Thomas Jefferson National Accelerator Facility & 1.963 & $-69 \% \nabla$ & 85 & $49 \% \Delta$ & 0.023 & $-79 \% \nabla$ & & \\
\hline Uranium Mill Tailings Remedial Action Project & 7.673 & $-49 \% \nabla$ & 87 & $-54 \% \nabla$ & 0.088 & $12 \% \Delta$ & & \\
\hline Waste Isolation Pilot Plant & 0.298 & $\diamond$ & 18 & $\diamond$ & 0.017 & $\diamond$ & & \\
\hline West Valley Demonstration Project & 9.312 & $-82 \% \nabla$ & 86 & $-65 \% \nabla$ & 0.108 & $-48 \% \boldsymbol{\nabla}$ & & \\
\hline Service Center Personnel* & 1.425 & $187 \% \Delta$ & 32 & $39 \%$ & 0.045 & $106 \%$ & & \\
\hline Totals & 718.453 & $-17 \% \nabla$ & 10,458 & $-19 \% \nabla$ & 0.069 & $3 \% \Delta$ & $13 \%$ & $2 \% \Delta$ \\
\hline
\end{tabular}

Note: Bold and boxed values indicate the greatest value in each column.

$\diamond$ The percentage change from the previous year is not shown because it is not meaningful when the site collective dose is less than 1 personrem (10 person-mSv). Please see section 3.4.3.1 for more information.

* Includes personnel at NNSA Albuquerque complex and Oak Ridge in addition to several smaller facilities not associated with a DOE site. 
The percentage of the collective TED above 0.500 rem is an indicator of the distribution of dose to individuals. A smaller fraction of the monitored population received doses above $0.5 \mathrm{rem}$ in 2012. See section 3.2.5 for more information on the characteristics of the distribution of doses to individuals above a certain dose value.

\subsubsection{Activities Significantly Contributing to Collective Dose in 2012}

In an effort to identify the reasons for changes in the collective dose at DOE, all of the larger sites were contacted to provide information on activities that significantly contributed to the collective dose for 2012. These sites (SRS, LANL, Oak Ridge, Hanford, and Idaho) each had a collective TED over 60 person-rems and were the top contributors to the collective TED in 2012. These sites comprised $81 \%$ of the total collective TED at DOE. Three sites reported decreases in the collective TED, which contributed to a $17.1 \%$ decrease in the DOE collective TED from 867 person-rems (8,670 person-mSv) in 2011 to 718 person-rems (7,180 person-mSv) in 2012 . The sites significantly contributing to the collective TED in 2012 are shown in Exhibit 3-15, including a description of activities that affected the collective TED.

Exhibit 3-15:

Activities Significantly Contributing to Collective TED in 2012.

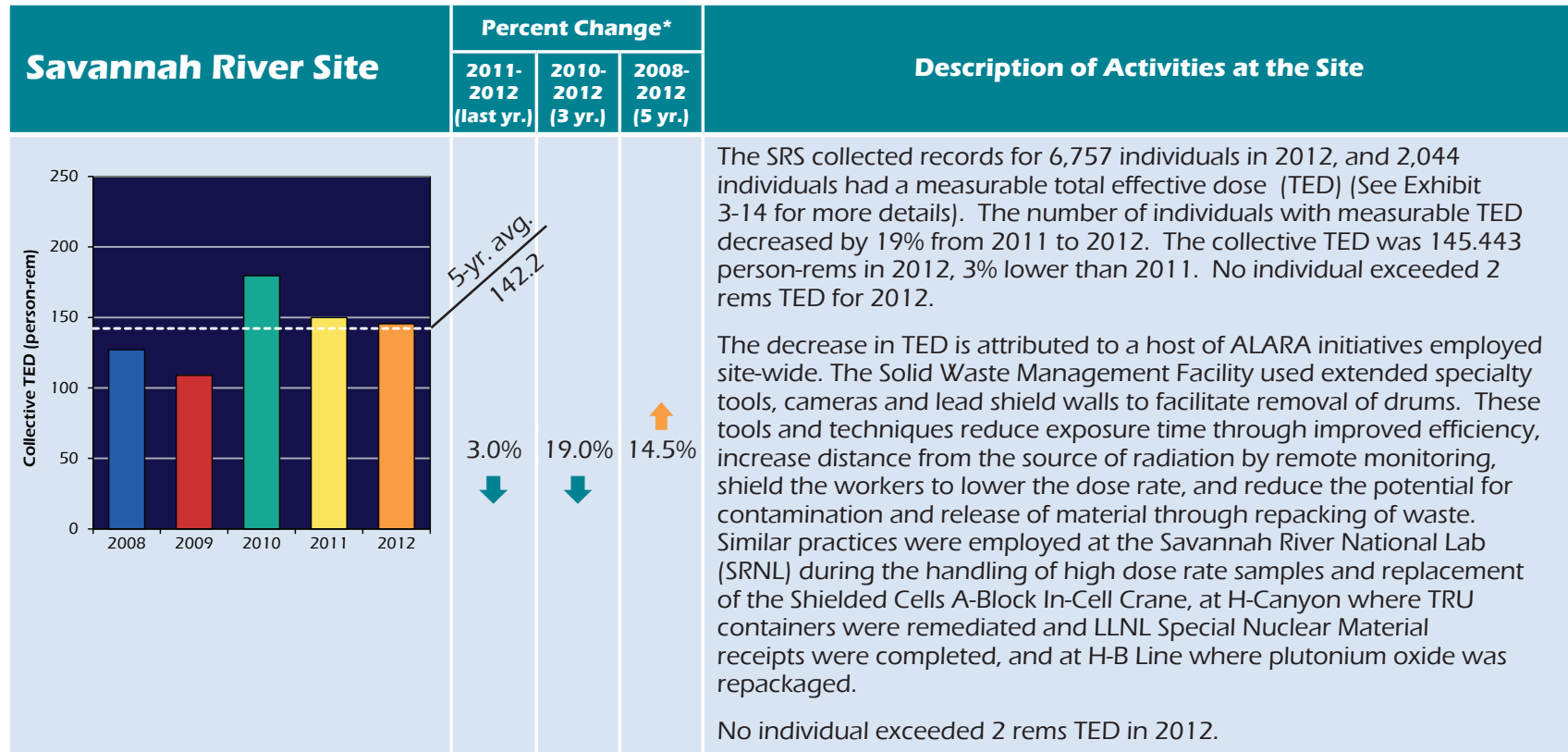

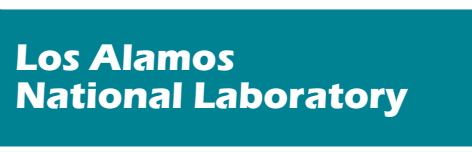

Percent Change*

\begin{tabular}{|c|c|c|}
\hline $2011-$ & $2010-$ & $2008-$ \\
2012 & 2012 & 2012 \\
(last yr.) & (3 yr.) & (5 yr.)
\end{tabular}

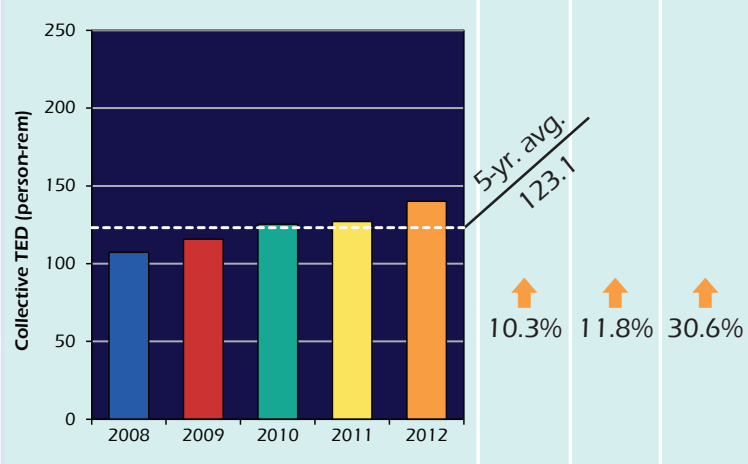

\section{Description of Activities at the Site}

LANL monitored 9,223 individuals, and of these, 1,438 had measurable TED, a 1\% decrease from 2011 (See Exhibit 3-14 for more details). Collective TED at LANL in 2012 was 140.148 person-rems, which is a $10 \%$ increase from the previous year.

TA-55 Plutonium Facility operations accounted for the majority of occupational dose at LANL in 2012, which is historically consistent for LANL. Occupational dose was accrued from manufacturing and related weapons work, Pu-238 work, repackaging materials, and providing RCT and other infrastructure support for radiological work and facility maintenance at TA-55. The primary contributor to increased dose was additional work with Pu-238, producing general purpose heat sources for use individually and in radioisotope thermoelectric generators. The top 10 doses at LANL in 2012 were attributed to Pu-238 work, and the top 25 doses were accrued at TA-55.

* Up arrows indicate an increase in change. Down arrows indicate a decrease in change. 
Exhibit 3-15 (Continued):

Activities Significantly Contributing to Collective TED in 2012.

Los Alamos
National Laboratory

Percent Change*

2011- $2010-12008-$

$20122012 \quad 2012$

\begin{tabular}{|c|c|c|}
2012 & 2012 & 2012 \\
(last $y r)$. & (3 yr.) & (5 yr.)
\end{tabular}
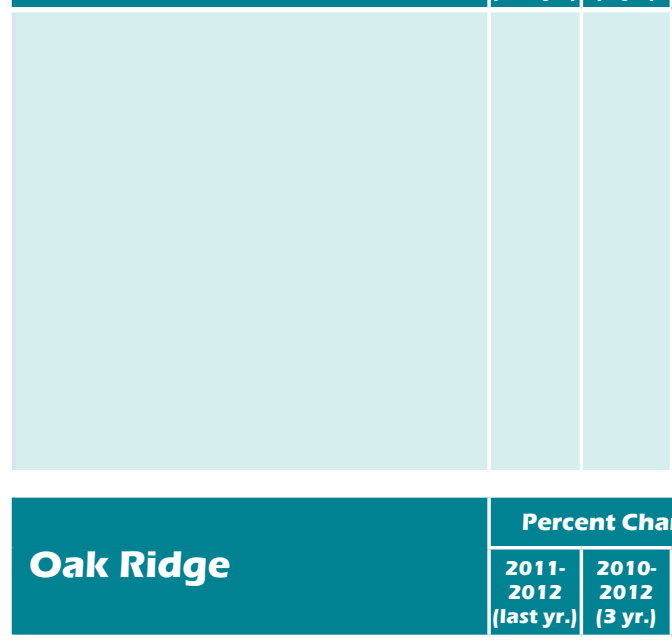

\section{Description of Activities at the Site}

In addition to TA-55 operations, a significant portion of LANL dose was accrued by workers performing retrieval, repackaging, and shipping of radioactive solid waste at LANL waste facilities at TA-50 and TA-54. This work increased commensurate with commitments to reduce onsite waste inventories. There was a significant portion of LANL dose accrued by workers performing programmatic and maintenance work at the TA-53 Los Alamos Neutron Science Center.

LANL extremity dose increased by $12 \%$, reflecting relatively more handson work in 2012 at TA-55 and waste handling operations at TA-50 and TA-54. Extremity doses are commensurate with work with significant quantities of radioactive material.

No individual received over 2 rems at LANL during 2012.

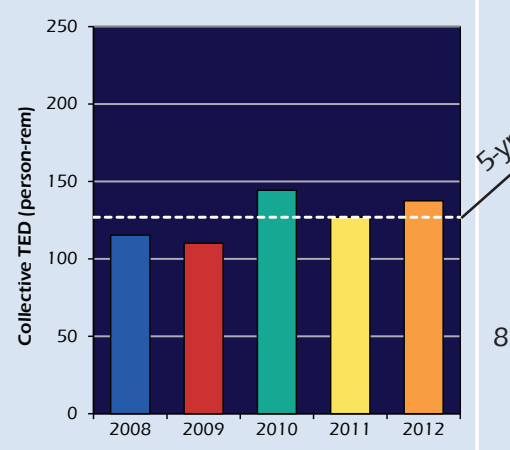

\section{Description of Activities at the Site}

\begin{tabular}{|c|c|c|}
\hline \multicolumn{3}{|c|}{ Percent Change' } \\
\hline & & \\
\hline & (3 yr. & $15 \mathrm{y}$ \\
\hline
\end{tabular}

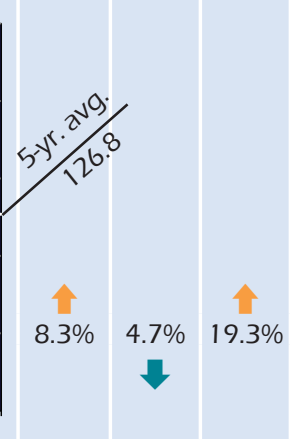

\section{Y-12 National Security Complex (Y-12)}

Over 6,300 individuals were monitored at Y-12 in 2012 (7\% fewer than in 2011 ) and 1,412 individuals had measurable TED, an $8 \%$ decrease from 2011 (See Exhibit 3-14 for more details). The collective TED decreased 1\% from 59.055 person-rems in 2011 to 58.245 person-rems in 2012 The 2012 collective CED increased 5\% from 44.6 person-rems in 2011 to 46.8 person-rems in 2012 . In production areas, there were multiple work stoppages throughout the year. Due to the stoppages, materials sat idle, increasing uptake potential upon each restart.

The 2012 collective effective dose for the $Y-12$ decreased $20 \%$ from 14.4 person-rems in 2011 to 11.5 person-rems in 2012. This decrease is mainly due to an overall decrease in production work with radioactive materials throughout the $Y-12$ complex in 2012. A steady decrease was visible each quarter of 2012 compared with 2011. A slightly greater decrease was evident in the third quarter when a security stand-down took place.

The total extremity dose decreased 10\% from 39.2 person-rems in 2011 to 35.3 person-rems in 2012.

No individual exceeded 2 rems TED in 2012

\section{Oak Ridge National Laboratory (ORNL)}

ORNL In 2012, ORNL reported 8,481 individuals, and of these, 764 individuals received a measurable TED (See Exhibit 3-14 for more details). This is a $5 \%$ increase in the number of individuals with measurable TED compared with 2011 . The collective TED for ORNL in 2012 was 78.792 person-rems. This represents an 18\% increase from 2011 (66.800 personrems).

During 2012, ORNL saw a decrease in isotope processing and maintenance activities at the High Flux Isotope Reactor (HFIR) and Spallation Neutron Source (SNS). The collective TED for laboratory personnel in 2012 was 26.951 person-rems, about 1\% less than 2011.

The collective TED for environmental restoration and D\&D employees located at ORNL was 5.614 person-rems. The decrease in TED for 2012 compared with 2011 reflects the completion of Tank W-1A remediation work activities, which accounted for most of the collective dose in 2011.

The transuranic waste processing center (TWPC), reported a collective TED of 34.778 person-rems for 2012.

The Hot Cells Project at ORNL reported a collective TED of 11.449 personrems for 2012.

\footnotetext{
* Up arrows indicate an increase in change. Down arrows indicate a decrease in change.
} 


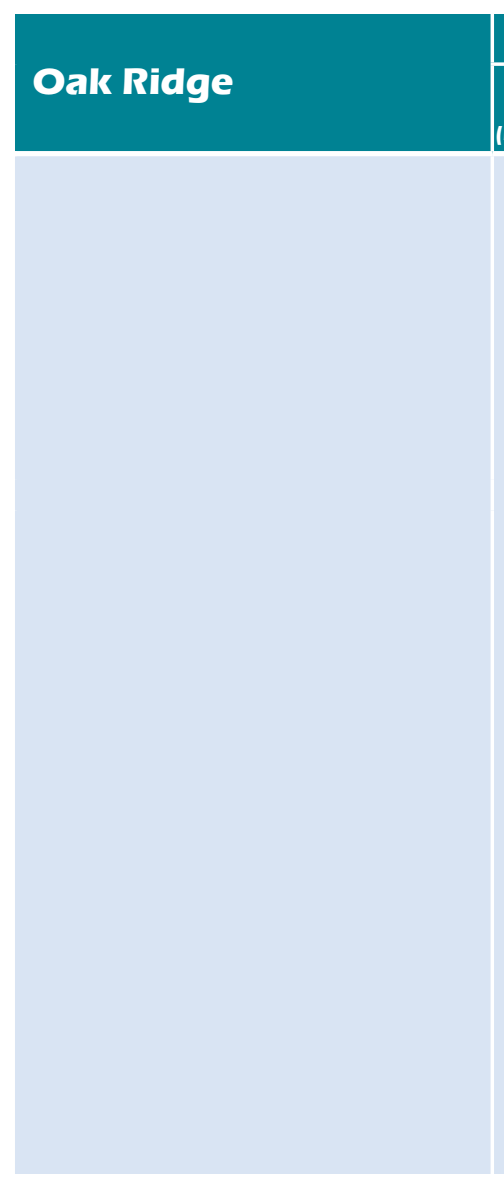

\begin{tabular}{|c|c|c|}
\hline \multicolumn{3}{|c|}{ Percent Change* } \\
\hline $2011-$ & $2010-$ & $2008-$ \\
2012 & 2012 & 2012 \\
(last yr.) & (3 yr.) & (5 yr.) \\
\hline
\end{tabular}

\section{Description of Activities at the Site}

\section{Oak Ridge Institute for Science and Education (ORISE)}

In 2012, ORISE reported 83 individuals, which includes 23 individuals with measurable dose (a 72\% decrease from 2011) (See Exhibit 3-13 for more details). The collective TED for the 2012 monitoring year was 0.124 person-rem, a $41 \%$ decrease from 2011 . In 2012, the number of classes that ORISE monitored for exposure decreased. Consequently, the number of individuals monitored decreased along with the total collective TED.

The majority of the dose was due to two major work projects. The first project was ARRA work being performed at various Oak Ridge sites, including K-27, K-25, and Isotope Row. The second project was work being performed for the Military Sealift Command on ships located at various areas throughout the world.

\section{East Tennessee Technology Park (ETTP)}

In 2012, the DOE cleanup contractor monitored 1,339 individuals and 14 individuals had measurable TED (a 64\% decrease from 2011) (See Exhibit 3-13 for more details). The 2012 collective TED was 0.306 person-rem, a 63\% decrease from 2011.

The major activities performed at DOE cleanup contractor-managed sites in 2012 consisted of environmental restoration work, decommission and decontamination of facilities, surveillance and maintenance tasks, stabilization of inactive facilities, and demolition of facilities.

The decrease in CED for 2012 compared with 2011 is associated with additional engineering controls imposed upon invasive work activities performed within K-25 prior to demolition activities. There were no unusual events related to occupational radiation exposure at ETTP facilities for 2012.

No individual exceeded 2 rems TED in 2012.

\section{Hanford}

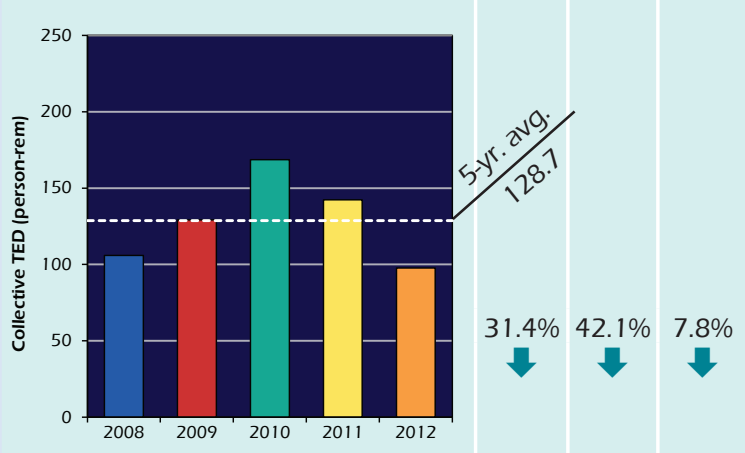

Percent Change

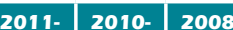

Overall, collective TED decreased by 31\% from 2011 to 2012 at Hanford. The primary reason for this change was due to the overall reduction of D\&D activities at the Hanford Site including Plutonium Finishing Plant and TRU retrieval activities. Neutron exposures decreased proportionately to the overall reduction in dose. Extremity dose decreased proportional to the decrease in neutron dose for Plutonium Finishing Plant (PFP) but increased for Tank Farm activities as a result of handling higher dose rate tank waste samples. The largest contributors to the Hanford exposure were glove box removal at the Plutonium Finishing Plant (37\%), Tank Farm activities (22\%), work activities at Pacific Northwest National

Laboratory (18\%), decontamination and demolition of various facilities on the river corridor and central plateau (12\%), and TRU retrieval and other Waste and Fuels operations (8\%).

\section{Hanford Site}

There were 5,235 individuals monitored at Hanford in 2012. Of these, 926 individuals had measurable TED, which is a 37\% decrease from 2011 (See Exhibit 3-14 for more details). The TED decreased 38\% from 94.691 person-rems in 2011 to 58.349 in 2012

No individual exceeded 2 rems TED in 2012.

* Up arrows indicate an increase in change. Down arrows indicate a decrease in change. 
Exhibit 3-15 (Continued):

Activities Significantly Contributing to Collective TED in 2012.

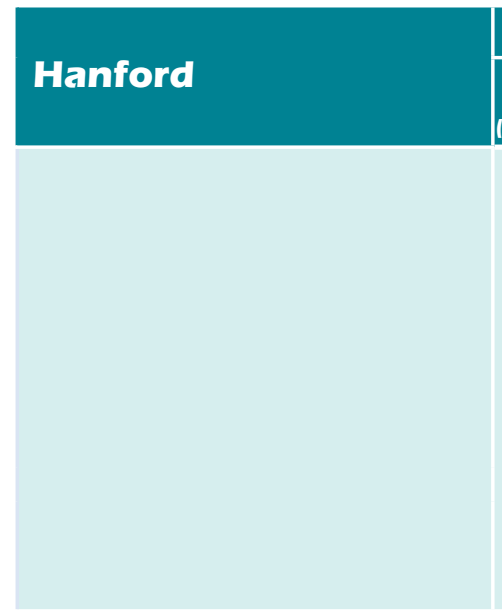

\begin{tabular}{|c|c|c|}
\hline \multicolumn{3}{|c|}{ Percent Change* } \\
\hline $\begin{array}{l}2010- \\
2011\end{array}$ & $\begin{array}{l}2009- \\
2011\end{array}$ & $\begin{array}{l}2007 \\
2011\end{array}$ \\
\hline last yr. & (3 yr.) & (5 yr.) \\
\hline
\end{tabular}

\section{Description of Activities at the Site}

\section{The Office of River Protection (ORP)}

In 2012, the ORP monitored 1,729 individuals, which included 413 individuals with measurable TED, a 17\% decrease from 2011 (See Exhibit 3-14 for more details). The 2012 collective TED decreased 15\% from 25.308 person-rems in 2011 to 21.528 person-rems in 2012.

No individual exceeded 2 rems TED in 2012.

\section{Pacific Northwest National Laboratory (PNNL)}

In 2012, PNNL monitored 1,946 individuals, and of these, 240 individuals had measurable TED, a 7\% decrease from 2011 (See Exhibit 3-14 for more details). The collective TED at PNNL in 2012 was 17.779 , a 20\% decrease from the previous year.

No individual exceeded 2 rems TED in 2012.

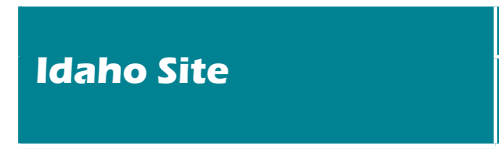

Percent Change*

2011- 2010 - 2008

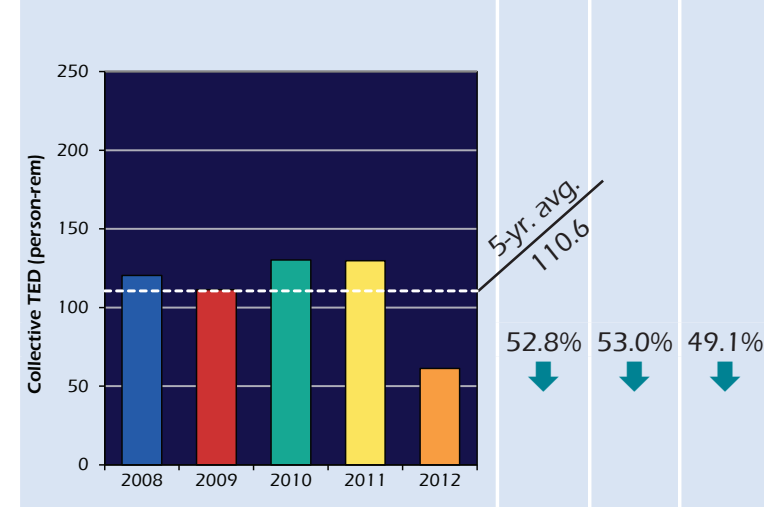

\section{Idaho National Laboratory}

In 2012, 3,590 individuals were monitored at the Idaho National Laboratory (INL), and of these, 765 individuals had measurable TED, a $46 \%$ decrease from 2011 . There was a collective TED of 37.129 personrems in 2012. This represents a decrease of approximately 30\% compared with 2011.

The radiation exposure activities performed during 2012 at the INL Site included work at the Advanced Test Reactor Complex, the Materials and Fuel Complex, and the Central and Idaho Falls Facilities.

Although dose at the Advanced Test Reactor Complex increased by 3.7 person-rems from 2011, TED decreased at the other facilities. The Materials and Fuel Complex dose was reduced in 2012 due to an extended area shutdown that began in April and lasted for several months. The shutdown was not radiologically related. Additionally, the number of Homeland Security/Defense Threat Reduction Agency (DTRA) training exercises held at the Central and Idaho Falls facilities have decreased since 2011 , resulting in less dose.

No individual exceeded 2 rems TED in 2012.

\section{Advanced Mixed Waste Treatment Project (AMWTP)}

In 2012, there were 877 persons monitored at AMWTP, and of these, 167 individuals had measurable TED, representing a 62\% decrease from 2011. The collective TED in 2012 was 9.492 person-rems. This represents a 53\% decrease from 2011.

The AMWTP work activities in 2012 continued the direct support of the 1995 Idaho/U.S. Navy/U.S. DOE Settlement Agreement requiring the removal of transuranic waste from the DOE's Idaho Site area. The primary work activities at the AMWTP that contributed to workforce dose included TRU waste retrieval, waste characterization, waste handling operations, and shipment of transuranic and by-product waste materials from Idaho to the DOE's WIPP facility and other commercial disposal sites. No significant radiological concerns were encountered in 2012.

This decrease in collective dose can be attributed to continuing improvements, planning of drum movements that reduced the number of times a container was handled prior to offsite disposal, placement of waste containers that created high radiation areas in a centralized location that was clearly identified, increased worker awareness of the location of elevated exposure rate areas by utilizing electronic dosimeters, and identifying drums that had an elevated exposure rate.

No individual exceeded 2 rems TED in 2012.

\footnotetext{
* Up arrows indicate an increase in change. Down arrows indicate a decrease in change.
} 


\begin{tabular}{|c|c|c|c|c|}
\hline \multirow[b]{2}{*}{ Idaho Site } & \multicolumn{3}{|c|}{ Percent Change* } & \multirow[b]{2}{*}{ Description of Activities at the Site } \\
\hline & \begin{tabular}{|c|}
$2011-$ \\
2012 \\
(last yr.)
\end{tabular} & $\begin{array}{l}2010- \\
2012 \\
\text { (3 yr. }\end{array}$ & $\begin{array}{c}2008- \\
2012 \\
\text { (5 yr.) }\end{array}$ & \\
\hline & & & & $\begin{array}{l}\text { Idaho Cleanup Project (ICP) } \\
\text { The DOE contractor at ICP submitted 1,463 records, which included } \\
310 \text { individuals with measurable dose (a } 40 \% \text { decrease from } 2011 \text { ). The } \\
\text { collective TED for } 2012 \text { was } 14.480 \text { person-rems. This represents a } 73 \% \\
\text { decrease from } 2011 \text { (53.251 person-rems). }\end{array}$ \\
\hline & & & & $\begin{array}{l}\text { ICP activities during } 2012 \text { leading to radiation exposure included waste } \\
\text { management activities, decontamination and decommissioning (D\&D) } \\
\text { activities, Accelerated Retrieval Project (ARP) exposure activities, Sludge } \\
\text { Repackaging Project exposure activities, and Idaho Nuclear Technology } \\
\text { and Engineering Center (INTEC) nuclear materials disposal. }\end{array}$ \\
\hline & & & & $\begin{array}{l}\text { Contributing factors to such a significant decrease in collective TED was a } \\
\text { much lower dose during D\&D activities. The reasons for the much lower } \\
\text { dose in } 2012 \text { included completion of high dose rate jobs, including the } \\
\text { TRA- } 632 \text { hot cell demo, and completion of handling the highly irradiated } \\
\text { EBR-II components. Additionally, exposure reduction at INTEC was due to } \\
\text { ALARA practices and reduction of work activities that involved radiation } \\
\text { exposure. }\end{array}$ \\
\hline & & & & No individual exceeded 2 rems TED in 2012 . \\
\hline & & & & $\begin{array}{l}\text { Department of Energy Idaho Operations Office } \\
\text { The Department of Energy Idaho Operations Office monitored } 195 \\
\text { individuals in } 2012 \text {, and of those, } 12 \text { individuals had measurable TED (a } \\
33 \% \text { increase from the } 9 \text { individuals in } 2011 \text { ). The collective TED for } 2012 \\
\text { was } 0.162 \text { person-rem, which is a } 36 \% \text { increase from } 2011 \text {. The largest } \\
\text { individual TED for the year was } 0.017 \text { rem. }\end{array}$ \\
\hline & & & & $\begin{array}{l}\text { Individuals with reported doses were primarily involved with oversight } \\
\text { in radiation buffer areas where a recorded access control entry is not } \\
\text { required, but a small amount of low-level occupational exposure is } \\
\text { possible. }\end{array}$ \\
\hline & & & & $\begin{array}{l}\text { No individual exceeded } 2 \text { rems TED (all DOE personnel received less than } \\
0.100 \text { person-rem in 2012). }\end{array}$ \\
\hline
\end{tabular}

In addition to the information provided in Exhibit 3-15, most of the DOE sites provided further information on operations conducted during the monitoring year. The REMS Reporting Guide, Item 1, specifies that the sites should provide a description of activities conducted at the site as it relates to the collective radiation exposure received. Twenty two sites reported a description of activities as it relates to occupational exposure. The full text of these descriptions can be found in Section 6. In this section, explanations for increases and decreases in the collective dose at DOE sites ranging from improved ALARA to changes in decommissioning activities are discussed. Overall, the majority of sites experienced decreases in collective dose.

\subsubsection{Summary by Program Office}

DOE has divided the responsibility of managing its missions among specific program offices. The various DOE sites support different missions and therefore fall under the authority and management of the corresponding program offices. It should be noted that several sites undertake work supporting multiple program offices. However, each site has a lead program office and is not required to report radiation exposure by program office, so the exact contribution from each program office cannot be determined. In these instances, the site is shown under one program office but may have significant portions of the dose from work done in support of other program offices. Exhibit 3-16 shows the number of individuals with measurable TED, the collective TED, and the average measurable TED by DOE program office. The Office of Environmental Management (EM) and the NNSA account for the largest percentages of the collective TED (47\% and 35\%, respectively). The mission of EM is to complete the safe cleanup of the environmental legacy brought about from five decades of nuclear weapons development and government-sponsored nuclear energy research. NNSA is responsible for the management and security of the 
Exhibit 3-16:

Program Office Dose Data, 2012.

\begin{tabular}{|c|c|c|c|c|c|c|c|c|c|}
\hline Program Office & $\begin{array}{l}\text { Collective } \\
\text { TED } \\
\text { (person- } \\
\text { rem) }\end{array}$ & $\begin{array}{l}\text { Percen } \\
\text { Change } \\
\text { from } 20\end{array}$ & & $\begin{array}{c}\text { Number } \\
\text { with } \\
\text { Meas. } \\
\text { Dose }\end{array}$ & $\begin{array}{r}\text { Percen } \\
\text { Chang } \\
\text { from } 20\end{array}$ & & $\begin{array}{l}\text { Avg. } \\
\text { Meas. } \\
\text { TED } \\
\text { (rem) }\end{array}$ & $\begin{array}{l}\text { Perce } \\
\text { Chang } \\
\text { from } 2 \mathrm{C}\end{array}$ & $\begin{array}{l}\text { int } \\
\text { ge } \\
011\end{array}$ \\
\hline \multicolumn{7}{|c|}{ Office of Energy Efficiency and Renewable Energy (EE) } & \multicolumn{3}{|c|}{ Total Monitored $=$} \\
\hline National Renewable Energy Laboratory & 0.020 & \multicolumn{2}{|l|}{$\diamond$} & 4 & \multicolumn{2}{|l|}{$\diamond$} & 0.005 & \multicolumn{2}{|l|}{$\diamond$} \\
\hline EE Totals* & 0.020 & \multicolumn{2}{|l|}{$\diamond$} & 4 & \multicolumn{2}{|l|}{$\diamond$} & 0.005 & \multicolumn{2}{|l|}{$\diamond$} \\
\hline \multicolumn{7}{|l|}{ Office of Environmental Management (EM) } & \multicolumn{3}{|c|}{ Total Monitored $=25,774$} \\
\hline East Tennessee Technology Park & 0.306 & \multicolumn{2}{|l|}{$\diamond$} & 14 & \multicolumn{2}{|l|}{$\diamond$} & 0.022 & \multicolumn{2}{|c|}{$\diamond$} \\
\hline Energy Technology Engineering Center & 0.226 & \multicolumn{2}{|l|}{$\diamond$} & 54 & \multicolumn{2}{|l|}{$\diamond$} & 0.004 & \multicolumn{2}{|c|}{$\diamond$} \\
\hline Hanford Site & 58.349 & $\begin{aligned} \diamond \\
300 \%\end{aligned}$ & $\boldsymbol{\nabla}$ & 926 & $-37 \%$ & & 0.063 & \multicolumn{2}{|l|}{$-2 \%$} \\
\hline Idaho Site (ICP and AMWTP) & 30.055 & \multicolumn{2}{|c|}{$-64 \% \nabla$} & 661 & $-51 \%$ & $\boldsymbol{\nabla}$ & 0.045 & \multicolumn{2}{|c|}{$-27 \% \nabla$} \\
\hline Oak Ridge National Laboratory & 46.227 & $50 \%$ & $\Delta$ & 310 & $12 \%$ & $\Delta$ & 0.149 & $35 \%$ & $\Delta$ \\
\hline Office of River Protection & 21.528 & $-15 \%$ & $\boldsymbol{\nabla}$ & 413 & $-17 \%$ & $\boldsymbol{\nabla}$ & 0.052 & $2 \%$ & $\Delta$ \\
\hline Paducah Gaseous Diffusion Plant & 5.984 & $48 \%$ & $\Delta$ & 113 & $45 \%$ & $\Delta$ & 0.053 & $2 \%$ & $\Delta$ \\
\hline Portsmouth Gaseous Diffusion Plant & 7.092 & $211 \%$ & $\Delta$ & 135 & $187 \%$ & $\Delta$ & 0.053 & $8 \%$ & $\Delta$ \\
\hline Savannah River Site & 145.443 & $-3 \%$ & $\boldsymbol{\nabla}$ & 2,044 & $-19 \%$ & $\boldsymbol{\nabla}$ & 0.071 & $19 \%$ & $\Delta$ \\
\hline Separations Process Research Unit & 0.584 & $\diamond$ & & 23 & $\diamond$ & & 0.025 & $\diamond$ & \\
\hline Service Center Personnel* & 1.388 & $\mathbf{2 1 8} \%$ & $\Delta$ & 30 & $50 \%$ & $\Delta$ & 0.046 & $112 \%$ & $\Delta$ \\
\hline Uranium Mill Tailings Remedial Action Project & 7.673 & $-49 \%$ & $\nabla$ & 87 & $-54 \%$ & $\boldsymbol{\nabla}$ & 0.088 & $12 \%$ & $\Delta$ \\
\hline Waste Isolation Pilot Plant & 0.298 & $\diamond$ & & 18 & $\diamond$ & & 0.017 & $\diamond$ & \\
\hline West Valley Demonstration Project & 9.312 & $-82 \%$ & $\boldsymbol{\nabla}$ & 86 & $-65 \%$ & $\boldsymbol{\nabla}$ & 0.108 & $-48 \%$ & $\boldsymbol{\nabla}$ \\
\hline EM Totals* & 334.465 & $-27 \%$ & $\boldsymbol{\nabla}$ & 4,914 & $-28 \%$ & $\boldsymbol{\nabla}$ & 0.068 & $1 \%$ & $\Delta$ \\
\hline National Nuclear Security Administration (NN) & & & & & & & Monito & $=32.4$ & 412 \\
\hline Kansas City Plant & 0.021 & $\diamond$ & & 6 & $\diamond$ & & 0.004 & $\diamond$ & \\
\hline Lawrence Livermore National Laboratory & 13.037 & $-23 \%$ & $\boldsymbol{\nabla}$ & 131 & $13 \%$ & $\Delta$ & 0.100 & $-32 \%$ & $\boldsymbol{\nabla}$ \\
\hline Los Alamos National Laboratory & 140.148 & $10 \%$ & $\Delta$ & 1,438 & $-1 \%$ & $\boldsymbol{\nabla}$ & 0.097 & $12 \%$ & $\Delta$ \\
\hline Nevada National Security Site & 4.284 & $56 \%$ & $\Delta$ & 100 & $28 \%$ & $\Delta$ & 0.043 & $22 \%$ & $\Delta$ \\
\hline Pantex Plant & 33.118 & $14 \%$ & $\Delta$ & 339 & $9 \%$ & $\Delta$ & 0.098 & $5 \%$ & 1 \\
\hline Sandia National Laboratories & 4.315 & $-38 \%$ & $\boldsymbol{\nabla}$ & 122 & $-3 \%$ & $\boldsymbol{\nabla}$ & 0.035 & $-36 \%$ & $\nabla$ \\
\hline Y-12 National Security Complex & 58.245 & $-1 \%$ & $\boldsymbol{\nabla}$ & 1,412 & $-8 \%$ & $\boldsymbol{\nabla}$ & 0.041 & $7 \%$ & $\Delta$ \\
\hline NNSA Totals* & 253.168 & $5 \%$ & $\Delta$ & 3,548 & $-2 \%$ & $\boldsymbol{\nabla}$ & 0.071 & $7 \%$ & $\Delta$ \\
\hline Office of Nuclear Energy (NE) & & & & & & & I Monito & $=2,7$ & 751 \\
\hline Idaho National Laboratory & 31.220 & $-32 \%$ & $\boldsymbol{\nabla}$ & 594 & $-44 \%$ & $\boldsymbol{\nabla}$ & 0.053 & $20 \%$ & $\Delta$ \\
\hline NE Totals* & 31.220 & $-32 \%$ & $\boldsymbol{\nabla}$ & 594 & $-44 \%$ & $\boldsymbol{\nabla}$ & 0.053 & $20 \%$ & $\Delta$ \\
\hline Office of Science (SC) & & & & & & & Monito & $=21,5$ & 524 \\
\hline Ames Laboratory & 0.820 & $\diamond$ & & 25 & $\diamond$ & & 0.033 & $\diamond$ & \\
\hline Argonne National Laboratory & 21.146 & $-28 \%$ & $\boldsymbol{\nabla}$ & 121 & $-32 \%$ & $\boldsymbol{\nabla}$ & 0.175 & $5 \%$ & $\Delta$ \\
\hline Brookhaven National Laboratory & 7.981 & $-38 \%$ & $\boldsymbol{\nabla}$ & 171 & $-1 \%$ & $\boldsymbol{\nabla}$ & 0.047 & $-37 \%$ & $\nabla$ \\
\hline Fermi National Accelerator Laboratory & 15.980 & $58 \%$ & $\Delta$ & 207 & $34 \%$ & $\Delta$ & 0.077 & $19 \%$ & $\Delta$ \\
\hline Lawrence Berkeley National Laboratory & 0.497 & $\diamond$ & & 10 & $\diamond$ & & 0.050 & $\diamond$ & \\
\hline New Brunswick Laboratory & 0.039 & $\diamond$ & & 2 & $\diamond$ & & 0.020 & $\diamond$ & \\
\hline Oak Ridge Institute for Science and Education & 0.124 & $\diamond$ & & 23 & $\diamond$ & & 0.005 & $\diamond$ & \\
\hline Oak Ridge National Laboratory & 32.565 & $-10 \%$ & $\nabla$ & 454 & $0 \%$ & & 0.072 & $-10 \%$ & $\nabla$ \\
\hline Pacific Northwest National Laboratory & 17.779 & $-20 \%$ & $\boldsymbol{\nabla}$ & 240 & $-7 \%$ & $\nabla$ & 0.074 & $-15 \%$ & $\nabla$ \\
\hline Princeton Plasma Physics Laboratory & 0.334 & $\diamond$ & & 43 & $\diamond$ & & 0.008 & $\diamond$ & \\
\hline Service Center Personnel* & 0.037 & $\diamond$ & & 2 & $\diamond$ & & 0.019 & $\diamond$ & \\
\hline SLAC National Accelerator Laboratory & 0.315 & $\diamond$ & & 15 & $\diamond$ & & 0.021 & $\diamond$ & \\
\hline Thomas Jefferson National Accelerator Facility & 1.963 & $-69 \%$ & $\boldsymbol{\nabla}$ & 85 & $49 \%$ & $\Delta$ & 0.023 & $-79 \%$ & $\nabla$ \\
\hline SC Totals* & 99.580 & $-17 \%$ & $\boldsymbol{\nabla}$ & 1,398 & $-5 \%$ & $\boldsymbol{\nabla}$ & 0.071 & $-13 \%$ & $\nabla$ \\
\hline
\end{tabular}

Note: Bold and boxed values indicate the greatest value in each column.

$\diamond$ The percentage change from the previous year is not shown because it is not meaningful when the site collective dose is less than 1 personrem (10 person-mSv). Please see section 3.4.3.1 for more information.

* The collective TED totals are calculated from the dose records that are reported in millirem while the values shown are rounded to the nearest tenth of a rem. 
nation's nuclear weapons, nuclear nonproliferation, and naval reactor programs, as well as responding to radiological emergencies and the transportation of nuclear weapons and special nuclear materials. In general, the missions of EM and NNSA require more interaction with and activities involving radioactive materials. These offices account for over $81 \%$ of the collective TED at DOE.

The primary sites contributing to the collective TED within EM are SRS and Hanford. For NNSA, the primary contributors are LANL and Y-12.

A more detailed breakdown of the exposure information by site, program office, and contractor is available at http://www.hss.doe.gov/SESA/Analysis/rems/ in the Appendices section of the Annual Report.

\subsection{Transient Individuals}

Transient individuals, or transients, are defined as individuals who are monitored at more than one DOE site during the calendar year. For the purpose of this report, a DOE site is defined as a geographic location. During the year, some individuals performed work at multiple sites and, therefore, had more than one monitoring record reported to the repository. In addition, some individuals transferred from one site to another. This section presents information on transient individuals to determine the extent to which individuals traveled from site to site and to examine the doses received by these individuals. Exhibit 3-17 shows the dose distribution and total number of transient individuals from 2008 to 2012 . Over the past 5 years, the records of transient individuals have averaged $3 \%$ of the total records for all monitored individuals at DOE. These individuals received, on an average, $4 \%$ of the collective TED. The collective TED for transients decreased 7\% from 31.7 person-rems (317 person-mSv) in 2011 to 29.4 person-rems (294 person-mSv) in 2012. The decrease of the collective TED is consistent with the overall decrease observed across the DOE complex from 2011 to 2012. The average measurable TED increased $7 \%$ from 0.056 rem $(0.56 \mathrm{mSv})$ in 2011 to $0.060 \mathrm{rem}(0.60 \mathrm{mSv})$ in 2012 . The increase of the average measurable TED is a result of the $13 \%$ decrease in the number with measurable dose and the 7\% decrease of the collective TED and is comparable with the increase observed in the average measurable TED across the DOE complex. Since 1993, the percentages have remained relatively constant, even though DOE has become extensively involved in D\&D activities and other types of operations.

The tracking and analysis of transient workers are important aspects of the HSS REMS project. While each site is responsible for monitoring individuals during their work at that site, the REMS project collects dose records from all sites and verifies that individuals do not exceed regulatory limits by accruing doses at multiple facilities. Although the numbers of transient individuals and average doses have been relatively low, the examination of these records remains an important function of HSS in ensuring individual worker health and safety.

Exhibit 3-17:

Dose Distribution of Transient Workers, 2008-2012.

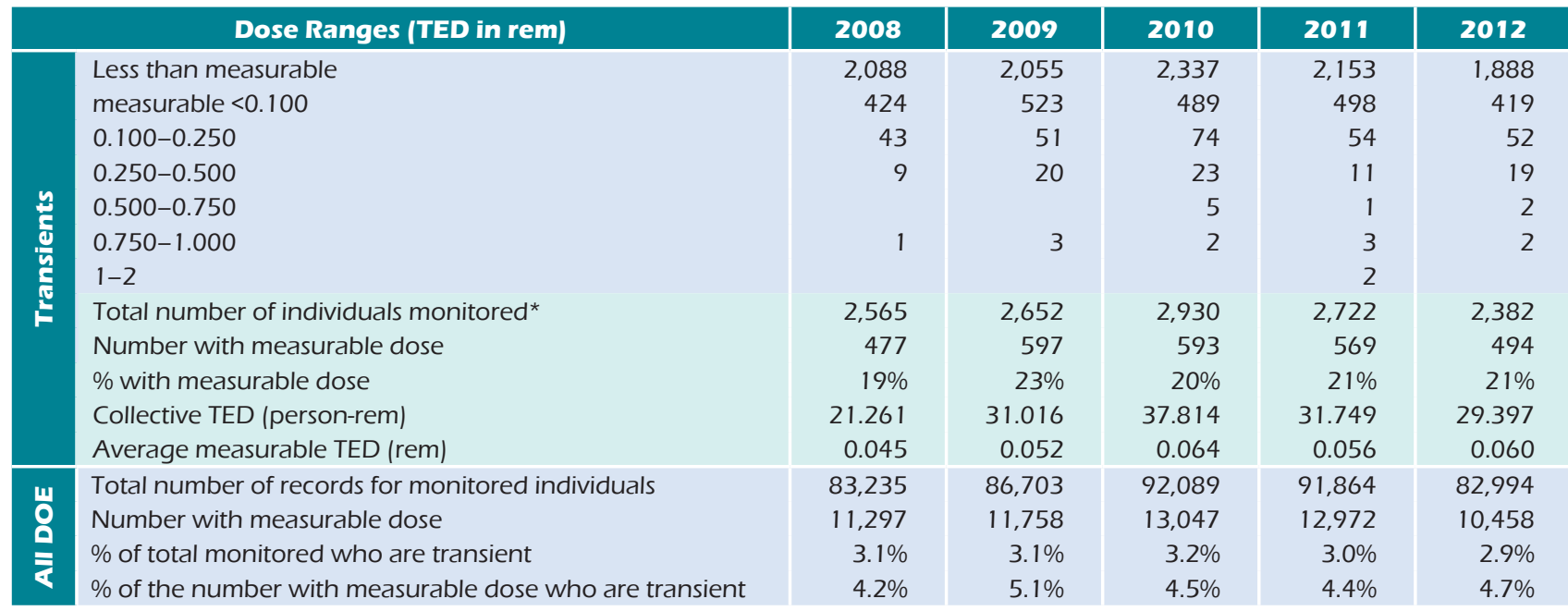

* Total number of individuals represents the number of individuals monitored and not the number of records. 


\subsection{Historical Data}

\subsubsection{Prior Years}

In order to analyze recent radiation exposure data in the context of the history of radiation exposure at DOE, it is useful to include information prior to the past 5 years as presented in this report. For this reason, Exhibit 3-18 and Exhibit 3-19 are presented to show a summary of occupational exposures back to 1974, when the Atomic Energy Commission split into the U.S. Nuclear Regulatory Commission (NRC) and the Energy Research and Development Administration, which subsequently became DOE. Exhibit 3-18 and Exhibit 3-19 show the collective dose, average measurable dose, and number of workers with a measurable dose from 1974 to 2012. As can be seen from the graphs, all three parameters decreased dramatically between 1986 and 1993. The main reasons for this large decrease were the shutdown of facilities within the weapons complex and the end of the Cold War era, which shifted the DOE mission from weapons production to shutdown, stabilization, and D\&D activities.

\subsubsection{Historical Data Collection}

In section 3.7 of the 2000 and 2001 annual reports on occupational exposure, information was presented on historical data that had been collected to date. Sites were requested by DOE to voluntarily provide historical exposure data, and many sites have subsequently responded. No additional sites reported historical data during the year 2012.

Sites that have not yet reported historical dose records are encouraged to contact Ms. Nirmala Rao at DOE (see section 1.2) to obtain further information on reporting these records. This is a request to voluntarily report historical data (records prior to 1987) that are available in electronic form or in whatever format that is most convenient for the site. The data will be stored as reported in REMS, and wherever possible, data will be extracted and loaded into the REMS database for analysis and retrieval. For detailed analysis, read section 3.7 of the 2000 report.

Sites that have voluntarily reported historical data are as follows:

\footnotetext{
Fernald Environmental Management Project;

$\checkmark$ Hanford Site;

- Idaho National Laboratory;
}

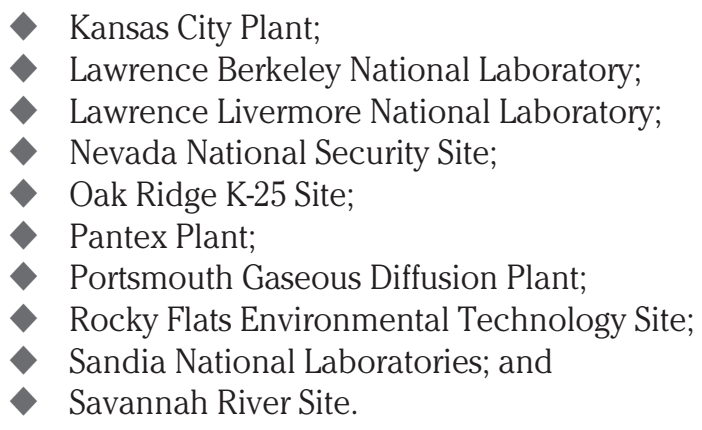

\subsection{DOE Occupational Dose in Relation to Other Activities}

\subsubsection{Activities Regulated by the U.S. Nuclear Regulatory Commission}

In the DOE Occupational Radiation Exposure Report 1992-1994, DOE occupational radiation exposure was shown in relation to other industrial and governmental endeavors in order to gain an understanding of the relative scale of the radiation exposure at DOE operations to other activities. The 2012 report includes the DOE occupational exposure in relation to activities regulated by the NRC. It should be noted that the purpose of this information is simply to put the DOE radiation exposure in context with other endeavors that involve radiation exposure. A direct comparison is not appropriate due to the differences in the missions of DOE and NRC. While the mission of DOE is broad in scope and includes activities from energy research to national defense, $\mathrm{NRC}$ licensed activities are dominated by radiation exposure received at commercial nuclear power plants. Reactor operations account for approximately $80 \%$ of the collective TED, while industrial radiographers, manufacturers, and distributors of radiopharmaceuticals, independent spent fuel storage installations, and fuel cycle licensees comprise the remainder.

The DOE and NRC occupational exposure data shown in Exhibit 3-20 cover the past 5 years (2008 to 2012). While the number of workers monitored at NRC and DOE are relatively comparable over the past 5 years, the number of individuals with a measurable dose at DOE was $18 \%$ of the NRC total for this time period. The percentages of DOE's collective dose (TED) and average measurable dose (TED) were $7 \%$ and $39 \%$ of the NRC totals, respectively. 


\section{Exhibit 3-18:}

Collective Dose and Average Measurable Dose, 1974-2012.

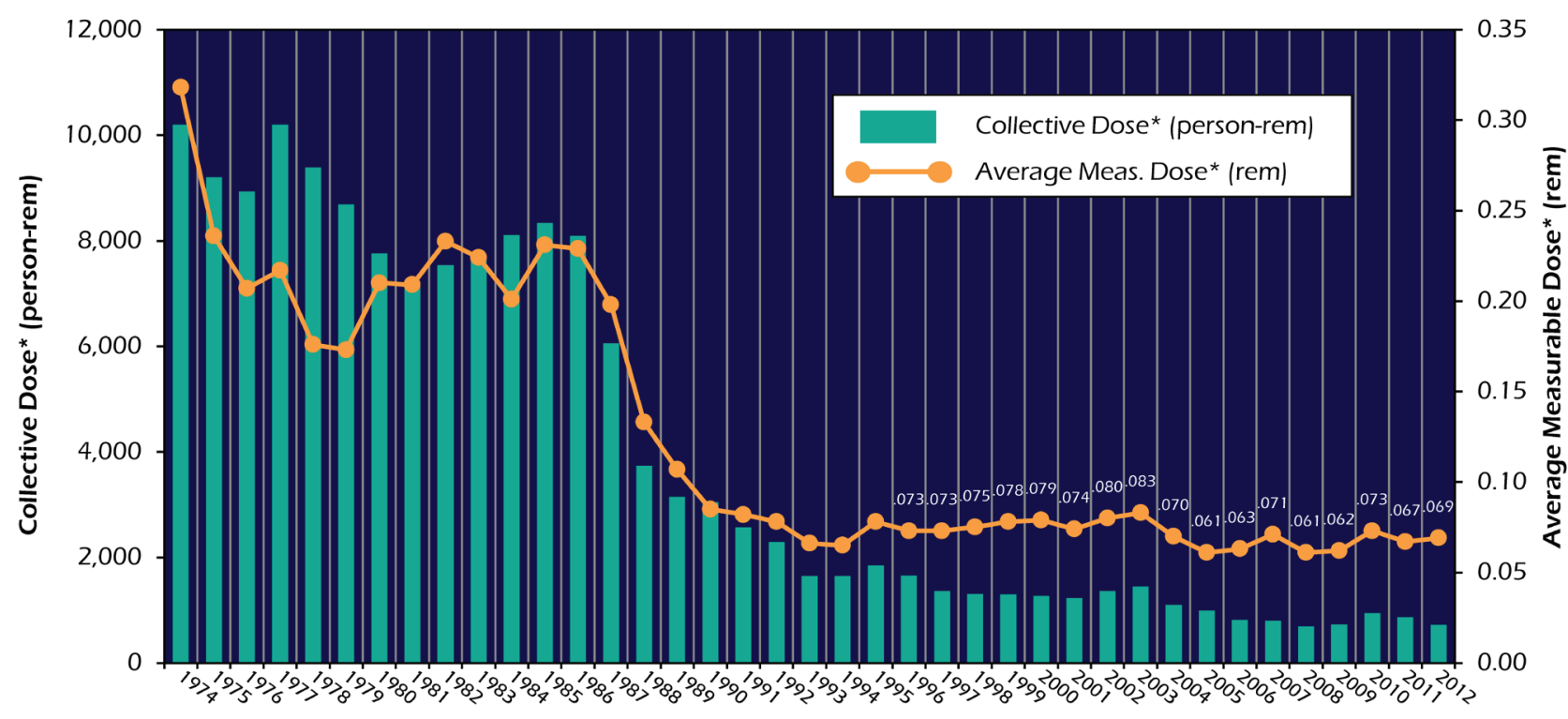

Year

\section{Exhibit 3-19:}

Number of Workers with Measurable Dose and Average Measurable Dose, 1974-2012.

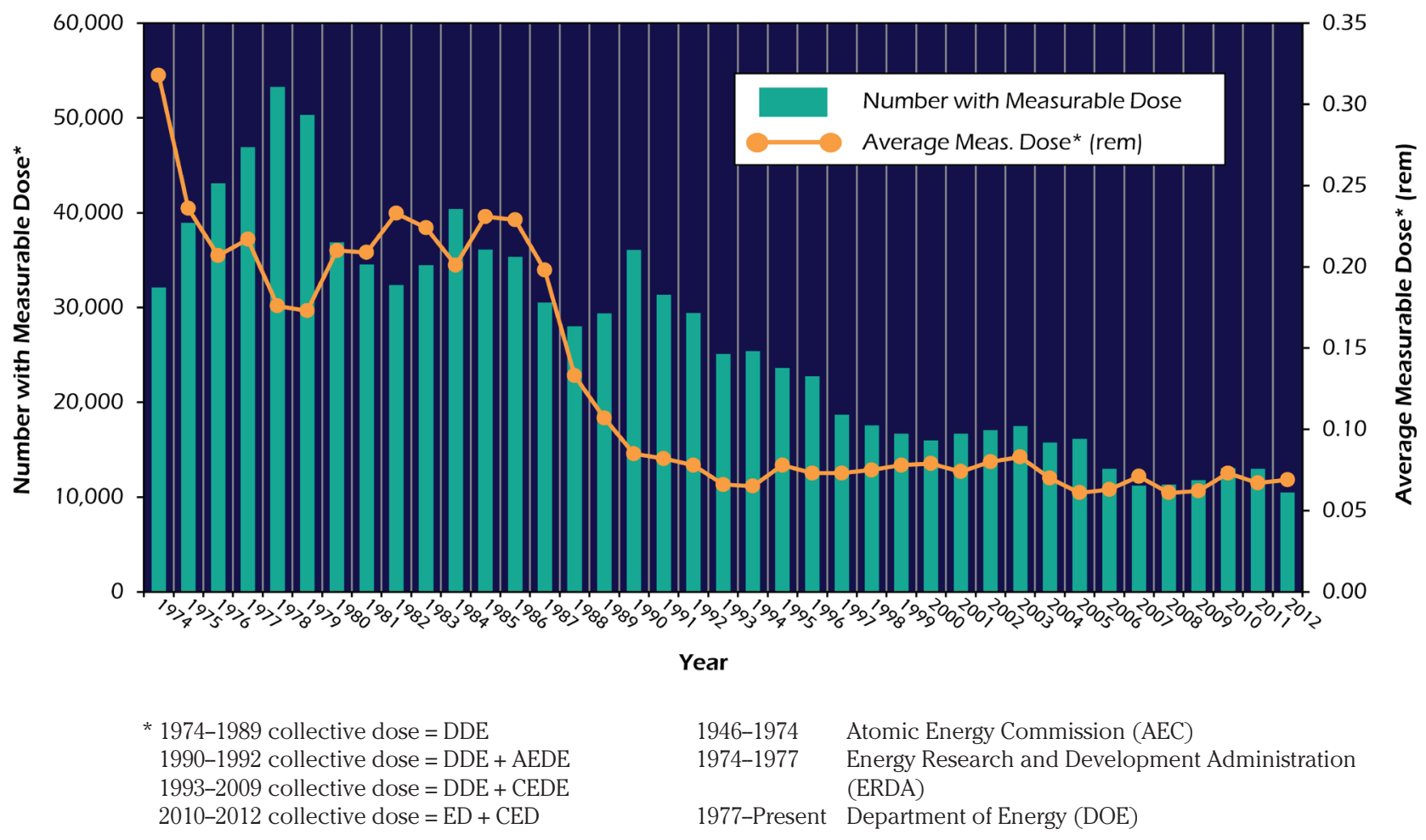


Exhibit 3-20:

Comparison of Occupational Exposure for DOE and NRC, 2008 -2012.
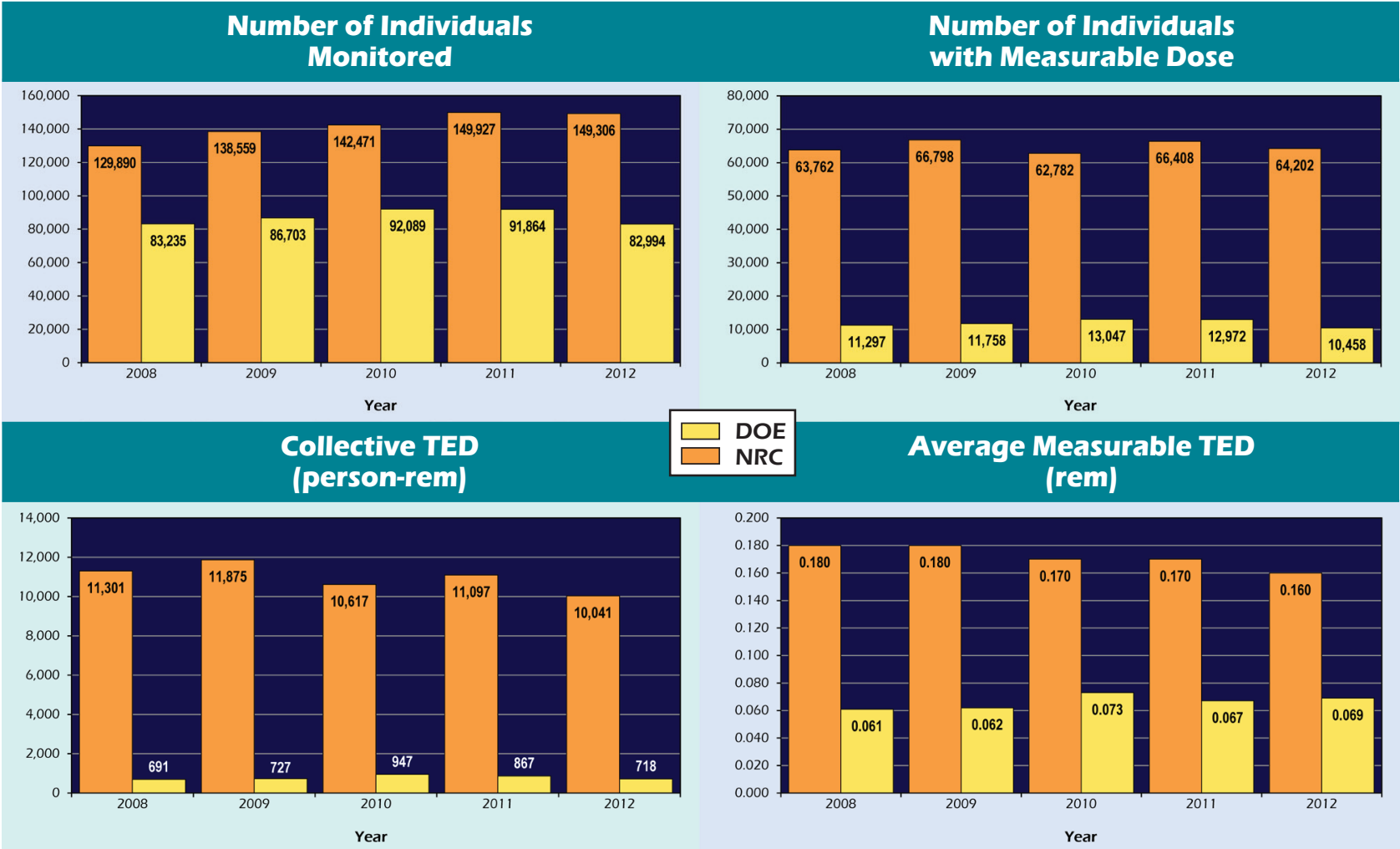


\section{ALARA Activities at DOE Ir}

Descriptions of ALARA activities at DOE are provided on the HSS web site for the purposes of sharing strategies and techniques that have shown promise in the reduction of radiation exposure and to facilitate the dissemination among DOE radiation protection managers and others interested in these project descriptions. Readers should be aware that the project descriptions are voluntarily submitted from the sites and are not independently verified or endorsed by DOE. Program and site offices and contractors who are interested in benchmarks of success and continuous improvement in the context of integrated safety management and quality are encouraged to provide input.

\subsection{Submitting ALARA Project Descriptions for Future Annual Reports}

Individual project descriptions may be submitted to the DOE Office of Analysis through the REMS web site. The submittals should describe the process in sufficient detail to provide a basic understanding of the project, the radiological concerns, and the activities initiated to reduce dose. The web site provides a form to collect the following information about the project:

$\checkmark$ Mission statement;

- Project description;

- Radiological concerns;

- Total collective dose for the project;

- Dose rate to exposed workers before and after exposure controls were implemented;

$\checkmark$ Information on how the process implemented ALARA techniques in an innovative or unique manner;

$\checkmark$ Estimated dose avoided;

- Project staff involved;

- Approximate cost of the ALARA effort;

- Impact on work processes, in person-hours if possible (may be negative or positive);

- Figures and/or photos of the project or equipment (electronic images if available); and

$\checkmark$ Point of contact for follow-up by interested professionals
The REMS web page for submitting ALARA project descriptions can be accessed on the Internet at:

http://www.hss.doe.gov/SESA/Analysis/rems/ rems/ALARA.pdf

\subsection{Operating Experience Program}

DOE has a mature operating experience program, which has been enhanced from the lessons learned program that was initially developed in 1994. The current DOE operating experience program is described in DOE O 210.2A, DOE Corporate Operating Experience Program [11]. The objective is to institute a DOE-wide program for the management of operating experience to prevent adverse operating incidents and to expand the sharing of good work practices among DOE sites. The purpose is to provide a systematic review, identification, collection, screening, evaluation, and dissemination of operating experience from U.S. and foreign government agencies and industry, professional societies, trade associations, national academies, universities, and DOE and its contractors. DOE Headquarters takes corporate responsibility for identifying, analyzing, and sharing operating experience information, combined with the operating experience/lessons learned provided by DOE field sites, and optimizes the knowledge gained and shared with others through various products, including a corporate database.

DOE posts operating experience information and links to other operating experience resources on the Internet. DOE uses the Internet to openly disseminate such information so that not only DOE but also other external entities will have a source of information to improve the health and safety aspects of operations within their facilities, including reducing the number of accidents and injuries. 
The specific operating experience web site address may be subject to change. Information services can be accessed through the HSS web site as follows:
http://www.hss.doe.gov/SESA/Analysis/II/

1000 Independence Avenue, SW

Washington, D.C. 20585-1290

E-mail: nimi.rao@hq.doe.gov 


\section{Conclustions}

The occupational radiation exposure records show that in 2012, DOE facilities continued to comply with DOE dose limits and ACLs and worked to minimize exposure to individuals. Only $13 \%$ of the monitored workers received a measurable dose and the average measurable dose was less than $2 \%$ of the DOE limit. In 2012, the collective dose and the number of individuals with measurable dose decreased $17.1 \%$ and $19 \%$, respectively. These decreases in the dose and number of individuals with measurable dose were the result of decreased activities involving radioactive materials, particularly at the DOE sites that comprise the majority of DOE collective dose. See Exhibit 5-1 below for summary data.

Over the past 5 years, the collective dose and the size of the monitored workforce have remained at fairly stable levels. The collective TED for all DOE facilities was reduced by 148 person-rems from 2011 to 2012 . This year marks the second time during the 5 year period that collective dose in the DOE complex decreased. Much of this can be attributed to a decline in ARRA activities, continuing D\&D progress with source term reduction and the absence of any events that exceeded the 2 rems occupational exposure limit.

The collective dose at DOE facilities has experienced a dramatic (92\%) decrease since 1986. This decrease coincides with the end of the Cold War era, which shifted the DOE mission from weapons production to stabilization, waste management, and environmental remediation activities, along with the consolidation and remediation of facilities across the complex to meet the new mission. It is notable that as DOE has become more involved in the new mission, collective and average doses have been relatively low. Also, during this time period, regulations have improved with an increased focus on ALARA practices and risk reduction.

Exhibit 5-1:

2012 Radiation Exposure Summary.

The collective TED decreased 17.1\% from 867 person-rems (8,670 person-mSv) in 2011 to 718 person-rems (7,180 person-mSv) in 2012.

- Sites contributing significantly to collective TED were (in descending order of collective TED) Savannah River, Los Alamos, Oak Ridge, Hanford, and Idaho. These sites accounted for 81\% of the collective TED at DOE in 2012.

$\checkmark$ The collective TED decreased at three of the five sites with the largest collective TED. For these three sites, the decrease in collective TED in 2012 was attributed to continuing improvements at the AMWTP at the Idaho Site through the planning of drum movements that reduced the number of times a container was handled, placement of waste containers that created high radiation areas in a centralized location, and increased worker awareness of high dose rate areas. In addition Idaho had the largest decrease in the total number of workers with measurable TED (1,143 fewer workers). At Hanford, the primary reason for the decrease in collective TED was the overall reduction of D\&D activities at the Plutonium Finishing Plant and Transuranic retrieval activities resulted in collective dose reductions. In addition, at Savannah River Site, the decrease was attributed to a host of ALARA initiatives employed site wide. Solid Waste Management Facility (SWMF) used extended specialty tools, cameras and lead shield walls to facilitate removal of drums. These tools and techniques reduce exposure time through improved efficiency, increase distance from the source of radiation by remote monitoring, shield the workers to lower the dose rate, and reduce the potential for contamination and release of material through repacking of waste.

- Sites attributed much of the decrease in collective dose to the winding down of ARRA activities and the continuing progress of D\&D projects in 2012.

The collective internal dose (CED) decreased by 7\% between 2011 and 2012.

- Uranium-234 accounted for the largest percentage of the collective CED, with over 93\% of this dose accrued at Y-12.

- The collective TED for transient workers decreased by 7\% from 31.7 person-rems (317 person-mSv) in 2011 to 29.4 person-rems (294 person-mSv) in 2012. 
This page intentionally left blank. 


\section{Additional Site Descriptions}

The following descriptions were provided by the sites not previously included in Exhibit 3-15. The REMS Reporting Guide, Item 1, specifies that the sites should provide a description of activities conducted at the site as it relates to the collective radiation exposure received.

Ames Laboratory is a government-owned, contractor-operated research facility of the U.S. Department of Energy. For more than 60 years, the Ames Laboratory has sought solutions to energy-related problems through the exploration of chemical, engineering, materials, mathematical, and physical sciences.

There were 166 individuals monitored in 2012, and of these, 25 individuals had measurable TED, a 14\% decrease from 2011. The collective TED was 0.820 person-rem in 2012, an $8 \%$ increase from 2011, even though there were four fewer individuals with measurable dose. No individuals exceeded 2 rems TED for this monitoring year.

The use of X-ray devices and remediation of radiological legacy contamination were the primary paths of potential exposure in 2012. The laboratory has 15 X-ray systems and one spectroscopy system. Limited radioactive material research activities were conducted utilizing microgram quantities. In the past year, some laser ablation work using radioactive material, irradiated metals activities, and electro transport purification work were conducted.

Argonne National Laboratory (ANL) is one of the U.S. Department of Energy's largest national laboratories for scientific and engineering research. The lab's mission is to apply a unique mix of world-class science, engineering, and user facilities to deliver innovative research and technologies.

There were 2,355 individuals monitored in 2012, and of these, 121 individuals had measurable TED, a 32\% decrease from 2011. The collective TED for the monitoring year 2012 at Argonne National Laboratory was 21.146 person-rems, which represents a decrease of 28\% from 2011. Collective TED at ANL has decreased by approximately 32\% since 2010.

The significant decrease was due to a resumption of normal activities in Nuclear and Waste Management, Facilities Management and Services, and Environment, Safety, and Quality Assurance. The dose incurred during the previous 2 years had been higher than typical as a result of radioactive waste removal activities at the Alpha Gamma Hot Cell Facility and associated site waste management operations.

Over the years a small group of about six technicians working at the Alpha Gamma Hot Cell Facility (AGHCF) have received external doses in excess of 0.500 rem/year (See Exhibit 3-14). This results in a high average dose for all Argonne workers receiving external dose. AGHCF programmatic work has ceased and accumulated radioactive materials such as fuel examination waste are currently being removed from the hot cell with cleanup to be substantially completed by the end of 2015 . As the inventory in the hot cell is reduced, the dose rate in the Clean Transfer Area (CTA) will also be reduced, so the elevated external doses will soon fall below $0.500 \mathrm{rem}$. The dose is accumulated during the waste removal campaigns. ALARA efforts include remote manipulator use and remote shielding cask operation; however entry into the CTA to complete the waste removal and to clean up residual loose contamination requires hands-on work in a High Radiation Area. Also, manipulator repair has been a source of external dose. 
Brookhaven National Laboratory (BNL) conducts research in the physical, biomedical, and environmental sciences, as well as in energy technologies and national security. BNL also builds and operates major scientific facilities available to university, industry, and government researchers.

There were 2,438 individuals monitored at BNL in 2012, and of these, 171 individuals had measurable TED, a $1 \%$ decrease from 2011. The collective TED decreased by $38 \%$ from 12.822 person-rems in 2011 to 7.981 person-rems in 2012. The highest individual dose was $0.526 \mathrm{rem}$. No individual exceeded 2 person rems TED or exceeded any DOE occupational dose limit. The CED in 2012 was zero person-rem.

The decrease in total dose and the reason for zero internal dose were primarily due to the shutdown of remediation activities at the Brookhaven Graphite Research Reactor (BGRR).

The Energy Technology Engineering Center (ETEC) is located within area IV of the Santa Susana Field Laboratory (SSFL). The SSFL is comprised of four discrete operational areas with two adjacent undeveloped properties. In 1988, DOE decided to close the remaining ETEC operations. With the closing of DOE operations, the focus turned to the disposition of government property, cleanup of facilities, the investigation and remediation of soil and groundwater, demolition of facilities, and site restoration. Area IV is undergoing characterization for cleanup of the area. ETEC is currently in a safe shutdown mode, pending the completion of the Environmental Impact Statement.

There were 82 individuals monitored at ETEC in 2012, and of these, 54 individuals had measurable TED, a 15\% increase over 2011. The collective TED increased by 63\% from 0.139 person-rem in 2011 to 0.226 person-rem in 2012. In 2012, few people received any significant radiation exposure dose from DOE operations. The reported numbers by the dosimeters were so close to the background and detection limit that the fluctuations were mainly due to the random noise of the monitoring process.

No individual exceeded 2 rems TED for this monitoring year.

Fermi National Accelerator Laboratory (Fermilab) advances the understanding of the fundamental nature of matter and energy by providing leadership and resources for qualified researchers to conduct basic research at the frontiers of high-energy physics and related disciplines.

In 2012, Fermilab reported 1,430 monitored individuals, and of these, 207 individuals had measurable TED, a 34\% increase compared with 2011. During 2012, the collective TED was 15.980 person-rems, which is a $58 \%$ increase from 2011.

During 2012, the primary activities at Fermilab that resulted in occupational radiation exposures were upgrade and repair activities of the Fermilab accelerator. Nearly all radiation doses to personnel were due to exposures to items activated by the accelerated beams. On May 1, 2012, Fermilab began a major maintenance and development shutdown for approximately 1 year to prepare the accelerator and associated facilities for new experiments at much larger beam powers to support research at the Intensity Frontier. Upgrades of several machines within the accelerator complex were performed, including the Linac, Booster, Recycler, Main Injector, and Neutrinos at the Main Injector (NuMI) areas. The accelerator shutdown was also necessary to repair many accelerator components following the final years of operation of the Tevatron colliding beam program and the high intensity NuMI beamline. Many of the changes made in this shutdown were also intended to improve operational reliability and, hence, reduced maintenance needs in the future. It has now been long recognized that the majority of doses to personnel result from shutdown conditions, as described above. 
The NNSA Kansas City Plant (KCP) is responsible for manufacturing and procuring nonnuclear components for nuclear weapons, including electronic, mechanical, and engineered material components. It supports national laboratories, universities, and U.S. industry, and is located in Kansas City, Missouri.

In 2012, KCP reported 70 monitored individuals, and of these, 6 individuals had measurable TED compared with 2 people with measurable TED in 2011. The collective TED was 0.021 person-rem, which represents a $57 \%$ decrease from 2011 . The maximum TED received by an individual was 0.006 rem.

No significant changes were made to the program and no individual exceeded 2 rems TED for this monitoring year.

Lawrence Berkeley National Lab (LBNL) is a member of the national laboratory system supported by the U.S. Department of Energy through its Office of Science and is charged with conducting unclassified research across a wide range of scientific disciplines. Located on a 200-acre site, Berkeley Lab employs approximately 4,200 scientists, engineers, support staff, and students.

The total number of employees monitored for radiation exposure at LBNL in 2012 was 769, and of these, 10 individuals had measurable TED, a 23\% decrease from 2011. The collective TED was 0.497 rem, a $35 \%$ decrease from 2011.

The primary reason for this change was due to the new shielded caves put into service in the Center for Functional Imaging (CFI). Ninety-three percent of the collective TED was the result of radiological activities at CFI, specifically those activities associated with new radiopharmaceutical (F-18/C-11) development.

Lawrence Livermore National Laboratory (LLNL) is a DOE facility that serves as a national resource of scientific, technical, and engineering capability with a special focus on national security. LLNL's mission encompasses such areas as strategic defense, energy, the environment, biomedicine, technology transfer, education, counter-terrorism, and emergency response. Support of these operations requires the use of a wide range of radiation-producing devices (e.g., x-ray machines, accelerators, electron-beam welders) and radioactive material. The types of radioactive materials range from tritium to transuranic; the quantities range from nanocuries (i.e., normal environmental background values) to kilocuries.

In 2012, 7,882 people were monitored at LLNL,and of these, 131 people had measurable TED, a 13\% increase from 2011. The collective TED for LLNL in 2012 was 13.037 person-rems, a 23\% decrease from 2011. This was due to decreased operations in the plutonium facility and at LLNL. There were three people with internal uptakes accounting for 0.035 person-rem total CED.

LLNL-Nevada is a DOE facility that serves as a national resource of scientific, technical, and engineering capability with a special focus on national security.

For 2012, LLNL-Nevada monitored 175 individuals and 1 person had measurable TED, the same as in 2011. The collective TED for LLNL-Nevada was 0.019 person-rem, representing a decrease of $82 \%$ from 2011. 
The New Brunswick Laboratory (NBL) is a Government-owned, Government-operated center of excellence in the measurement science of nuclear materials. Specific operations involving radioactive material include destructive and nondestructive measurements of nuclear materials including plutonium and uranium. Additionally, NBL conducts research to develop improved measurement technology applied to nuclear materials and management of interlaboratory measurement evaluation programs.

In 2012, NBL monitored 29 individuals, and of these, 2 individuals had measurable TED, a $75 \%$ decrease from 2011. The collective TED at NBL for 2012 was 0.039 person-rem. This represents a $76 \%$ decrease from 2011 ( 0.165 person-rem) and is attributed to the annual physical inventory of nuclear material.

The Nevada National Security Site (NNSS) is located approximately 65 miles northwest of Las Vegas. It is a remote facility that covers approximately 1,375 square miles of land. The NNSS has been the primary location for testing nuclear experiments in the continental United States since 1951. Current activities include operating low-level radioactive and mixed waste disposal facilities; assembly and execution of subcritical experiments; confined critical experiments; assembly/disassembly of special experiments; operation of pulsed x-ray machines and neutron generators; accelerator experiments; development, testing, and evaluation of radiation detectors; emergency response training; surface cleanup and site characterization of contaminated land areas; environmental activity; and non-nuclear test operations such as controlled spills of hazardous materials.

In 2012, NNSS monitored 2,984 people, and of these, 100 people had a measurable TED, a $28 \%$ increase compared with 2011. The highest individual dose was 0.296 rem. The collective TED for 2012 at NNSS was 4.284 person-rems, which represents a 56\% increase in TED from 2011. No individual had a measurable committed effective dose (CED) from internally deposited material.

The increase in dose was primarily due to handling sealed radioactive sources and from receiving and staging fuel plates for storage within an onsite facility at the NNSS. The receipt of these fuel plates from Oak Ridge National Laboratory began in late 2011 and increased in frequency during the first and second quarters of 2012.

The National Renewable Energy Laboratory (NREL) focuses on creative answers to today's energy challenges. From fundamental science and energy analysis to validating new products for the commercial market, NREL researchers are dedicated to transforming the way the world uses energy. With more than 35 years of successful innovation in energy efficiency and renewable energy, NREL discoveries provide sustainable alternatives for powering homes, businesses, and transportation systems.

In 2012, NREL monitored 14 people, and of these, 4 people had a measurable TED, a 20\% decrease from 2011. The collective TED increased by 18\% from 2011 to 2012 (0.020 person-rem).

The primary reason for this change was due to an increase in work involving radiation exposure. 
The Paducah Gaseous Diffusion Plant (PGDP) is located 3 miles south of the Ohio River and is 12 miles west of Paducah, Kentucky. The plant began enriching uranium in 1952 first for the nation's nuclear weapons program, then for nuclear fuel for commercial power plants. Since that time, the plant has run continuously. Paducah remains the only operating gaseous diffusion uranium enrichment plant in the United States.

In 2012, the PGDP monitored 1,044 individuals, which included 113 individuals with measurable TED, a $45 \%$ increase compared with 2011. The overall collective TED for the PGDP was 5.984 person-rems, a $48 \%$ increase from 2011. The following description provides a breakdown of the various activities at this site.

The DOE remediation services contractor's exposure information for 2012 covers activities performed under the DOE contract and includes environmental remediation, facility decontamination, and final assessment of buildings and areas at the Paducah Site.

The collective TED for 2012 was 0.109 person-rem. This represents a 129\% decrease from the previous year. The primary reason for this change was decreased facility decontamination and decommissioning operations at Paducah. The number of individuals exceeding 2 rems TED for 2012 was zero. There were no unusual events related to occupational radiation exposure for 2012.

The DOE DUF ${ }_{6}$ contractor's collective TED for 2012 was 5.531 person-rems. This represents a 46\% increase from 2011. The primary reason for this change was increased start-up operations at the Paducah DUF $_{6}$ Conversion Facility. The number of individuals exceeding 2 rems TED for 2012 was zero. There were no unusual events related to occupational radiation exposure for 2012.

The DOE oversight contractor's collective TED for the 2012 monitoring year was 0.344 person-rem. This represents a $575 \%$ increase from the value for the previous monitoring year. The primary reason for this change was due to a change in the scope of work that provided dosimetry for some individuals to perform duties such as oversight and escorting at the Depleted Uranium Facility. There was no change in the exposure levels for individuals performing normal work operations.

The DOE/NNSA Pantex Plant is the nation's only facility for assembly and disassembly of nuclear explosives. The operations that contribute the majority of the dose to Pantex Plant workers are operations that expose them to large numbers of bare weapon pits (the pits contain significant quantities of Special Nuclear Materials). These operations include nuclear explosive assembly/ disassembly operations, weapon dismantlement programs, life-extension programs, Special Nuclear Material Component Requalification, and Special Nuclear Material staging.

In 2012, Pantex monitored 3,427 individuals, and of these, 339 individuals had measurable TED, a 9\% increase from 2011. The TED to Pantex Plant workers in 2012 was 33.118 person-rems, which represents a $14 \%$ increase above the total person-rem dose in 2011. No individual's dose exceeded their assigned administrative control level in 2012, with a maximum individual dose of $0.703 \mathrm{rem}$.

The primary reason for the increased population dose in 2012 was the increase in the workload accomplished. 
The Portsmouth Gaseous Diffusion Plant (PORTS) is located in Pike County, Ohio, in southern central Ohio. PORTS was one of three large gaseous diffusion plants initially constructed to produce enriched uranium to support the nation's nuclear weapons program and later enriched uranium used by commercial nuclear reactors.

In 2012, Portsmouth monitored 3,864 individuals, which included 135 people with measurable TED, a $187 \%$ increase from 2011. The collective TED in 2012 at PORTS was 7.092 person-rems, a 211\% increase compared with 2011.

The primary reason for this change was the increased start-up to full operations at the Piketon DUF Conversion Facility during calendar year 2012, whereas operations only occurred periodically during calendar year 2011. The number of individuals exceeding 2 rems TED for 2012 was zero.

The U.S. Department of Energy's Princeton Plasma Physics Laboratory (PPPL) is a collaborative national center for fusion energy research. The Laboratory advances the coupled fields of fusion energy and plasma physics research and with collaborators, is developing the scientific understanding and key innovations needed to realize fusion as an energy source for the world.

In 2012, data were submitted for 346 individuals, and of these, 43 individuals had measurable TED, a 19\% decrease compared with 2011. The collective TED to monitored employees in 2012 was 0.334 person-rem, a 17\% decrease from 2011.

The primary source for exposure was due to the continuing National Spherical Torus Experiment (NSTX) construction activities in both the NSTX test cell and the old Tokamak Fusion Test Reactor test cell, as components and materials were activated during normal operations.

SLAC National Accelerator Laboratory (SLAC) scientific mission centers around experimental and theoretical research in elementary particle physics using accelerated electron beams and a broad program of research in atomic and solid-state physics, chemistry, and biology using synchrotron radiation from accelerated electron beams. The main instrument of research is the $3.2-\mathrm{km}$ linear accelerator, which can generate high-intensity beams of electrons and positrons up to $50 \mathrm{GeV}$.

The construction of the new Facilities for Accelerator Science and Experimental Test (FACET) was completed in mid-2012 to study plasma acceleration, using short, intense pulses of electrons and positrons to create an acceleration source called a plasma wakefield accelerator. FACET beams at SLAC have been operated since June 2012.

The 2012 report contained 2,266 records, which included 15 people with measurable TED, a 50\% increase compared with 2011. Collective TED in 2012 was 0.315 person-rem, a 33\% increase compared with 2011. No individual exceeded 2 person-rems TED or any DOE occupational dose limit during 2012 at SLAC.

This increase was mainly associated with the operations of the newly constructed Facilities for the Accelerator Science and Experimental Test facility. 
Sandia National Laboratories (SNL) radiological operations include operation of a research reactor, gamma irradiation facility, hot cell facility, several accelerators, light laboratory work involving x-ray machines and use of tracer radionuclides, and waste operations.

In 2012, SNL monitored 2,592 individuals, and of these, 122 individuals had measurable TED, a 3\% decrease from 2011. The 2012 collective TED for SNL was 4.315 person-rems, a 38\% decrease from 2011.

This decrease can be attributed to a 2012 reduction in Auxiliary Hot Cell Facility (AHCF) TRU waste processing campaigns and Annular Core Research Reactor (ACRR) special irradiation projects.

The Separations Process Research Unit (SPRU) is located at Knolls Atomic Power Laboratory (KAPL) based in upstate New York. Built in the 1940s, the buildings supported the SPRU mission to research the chemical process to extract plutonium from irradiated materials. Although equipment was flushed and drained and bulk waste was removed following the shutdown of the facilities in 1953, residual materials are present in the tanks, buildings $\mathrm{H} 2$ and $\mathrm{G} 2$, and interconnecting pipe tunnels.

Demolition activities were halted at the end of September 2010. The project activities in 2012 were the continued surveillance and maintenance activities to maintain site condition, the processing and shipment of low activity water, shipping of low activity soil and debris, installing the piping and equipment necessary to allow pumping of G2 basement water, and the continued tenting of G2 and $\mathrm{H} 2$ buildings in preparation for demolition activities. The additional activities resulting in the major person-rem contribution were the removal and packaging of the old sludge processing equipment in the Sludge Processing Tent (SPT) and erecting of the H2/G2 tunnel wall.

In 2012, SPRU monitored 272 individuals, and of these, 23 had measurable TED, a 77\% increase compared with 2011. The collective TED for 2012 was 0.584 person-rem, a 226\% increase from 2011.

The primary reasons for this change were due to significant activity in the SPT to remove and package the old sludge processing equipment, which accumulated $157 \mathrm{mRem}$ by ED, and work in the H2/ G2 tunnel to remove process piping and install an isolation wall separating the $\mathrm{H} 2$ and $\mathrm{G} 2$ enclosures ventilation path, which accumulated 0.392 rem by ED.

Thomas Jefferson National Accelerator Facility (TJNAF) is one of 17 national laboratories funded by DOE. TJNAF's primary mission is to conduct basic research of the atom's nucleus using the unique particle accelerator known as the Continuous Electron Beam Accelerator Facility.

In 2012, TJNAF monitored 1,422 individuals, which included 85 individuals with measurable TED, a 49\% increase from 2011. The 2012 collective TED for TJNAF was 1.963 person-rems, a decrease of $69 \%$ from 2011. The 2012 collective TED value falls within Jefferson Lab's expected range. No individual dose exceeded the TJNAF administrative control level of 1 rem and the highest measurable dose was 0.120 rem.

In general, the 2012 collective TED is attributed to TJNAF's long shut down and the maintenance, modification, and repair to activated components associated with the Continuous Electron Beam Accelerator Facility and other ancillary activities (e.g., transport, storage, and disposal of radioactive materials). Typically, collective TED fluctuates up or down from year to year depending on maintenance associated with unique experimental set-ups performed in radiation areas. 
The Uranium Mill Tailings Remediation Action Project (UMTRA) site is located approximately 3 miles northwest of Moab in Grand County, Utah, and includes a former uranium-ore processing facility. The site encompasses 480 acres, of which approximately 130 acres are covered by a uranium mill tailings pile. The UMTRA Project ships one trainload of tailings each day. The trains have up to 36 railcars, each holding four lidded containers, for a total of about 5,000 tons of tailings per shipment. Tailing shipments began in April 2009 and are expected to continue through 2025.

In 2012, UMTRA monitored 158 individuals, which included 87 individuals with measurable TED, a 54\% decrease from 2011. The collective TED for 2012 was 7.673 person-rems and represents a $49 \%$ decrease from 2011 (15 person-rems TED).

The primary reason for this decrease was due to a change in the scope of work; a 3-month curtailment period was inserted along with some non-operational down time. This process also decreased the number of monitored workers from 160 workers down to 111 monitored workers.

The Waste Isolation Pilot Plant (WIPP) is located in the Chihuahuan Desert near Carlsbad, New Mexico. This DOE facility safely disposes of the nation's defense-related transuranic radioactive waste. WIPP began disposal operations in March 1999.

In 2012, WIPP monitored 1,009 individuals, and of these,18 individuals had measurable TED, a 28\% decrease compared with 2011. The collective TED for 2012 was 0.298 person-rem, which represents a $37 \%$ decrease from 2011 (0.476 person-rem).

The primary reason for this decrease was due to changes in the amount of radioactive material contained in the waste processed at WIPP. All doses received were from routine activities associated with the disposal of transuranic waste. There were no individuals exceeding 2 rems TED for this monitoring year.

The West Valley Demonstration Project (WVDP) is a unique operation within DOE. It came into being through the West Valley Demonstration Project Act of 1980. The Act requires that the Department is responsible for solidifying the high-level waste, disposing of waste created by the solidification and decommissioning the facilities used in the process. The land and facilities are not owned by the Department. Rather, the project premises are the property of the New York State Energy Research and Development Authority (NYSERDA) and represent only 200 acres of the larger Western New York Service Center, which is approximately 3,300 acres, also owned by NYSERDA. After DOE's responsibilities under the Act are complete, the Act requires that the premises be returned to New York State.

In 2012, WVDP monitored 331 individuals, and of these, 86 individuals had measurable TED, a $65 \%$ decrease from 2011. The collective TED for 2012 was 9.312 person-rems, which represents an $82 \%$ decrease from 2011.

The major contribution to dose in 2012 was waste operations activities, including waste processing, packaging, and shipping for disposal radioactive waste previously produced during decontamination \& decommissioning (D\&D) projects. The primary reason for this change was due to a decreased level of high dose work performing D\&D in former process cells. 


\section{Glossarys Sary}

administrative control level (ACL)

A dose level that is established below the DOE dose limit in order to administratively control exposures. ACLs are multi-tiered, with increasing levels of authority required to approve a higher level of exposure.

\section{ALARA}

Acronym for "as low as is reasonably achievable," which is the approach to radiation protection to manage and control exposures (both individual and collective) to the workforce and the general public to as low as is reasonable, taking into account social, technical, economic, practical, and public policy considerations. ALARA is not a dose limit but a process with the objective of attaining doses as far below the applicable limits as is reasonably achievable.

\section{American Recovery and Reinvestment Act (ARRA)}

The ARRA of 2009 is an economic stimulus package signed into law on February 27, 2009.

\section{average measurable dose}

Dose obtained by dividing the collective dose by the number of individuals who received a measurable dose. This is the average most commonly used in this and other reports when examining trends and comparing doses received by workers, because it reflects the exclusion of those individuals receiving a less than measurable dose. Average measurable dose is calculated for total effective dose (TED), effective dose (ED), neutron dose, extremity dose, and other types of dose.

\section{collective dose}

The sum of the total annual effective dose equivalent or total effective dose values for all individuals in a specified population. Collective dose is expressed in units of person-rem.

\section{committed effective dose (CED) $\left(\mathrm{H}_{\mathrm{E}}, \mathbf{5 0}\right)$}

The sum of the committed equivalent doses to various tissues or organs in the body $\left(\mathrm{H}_{\mathrm{T}}, 50\right)$, each multiplied by the appropriate tissue weighting factor $\left(\mathrm{w}_{\mathrm{T}}\right)$ (i.e., $\left.\mathrm{H}_{\mathrm{E}}, 50=\mathrm{w}_{\mathrm{T}} \mathrm{H}_{\mathrm{T}}, 50\right)$. CED is expressed in units of rem.

\section{committed equivalent dose (CEqD) $\left(\mathrm{H}_{\mathrm{T}}, \mathbf{5 0}\right)$}

The equivalent dose calculated to be received by a tissue or organ over a 50-year period after the intake of a radionuclide into the body. It does not include contributions from radiation sources external to the body. $\mathrm{CEqD}$ is expressed in units of rem.

\section{CR}

See SR.

\section{ED}

The summation of the products of the ED received by specified tissues or organs of the body $\left(\mathrm{H}_{\mathrm{T}}\right)$ and the appropriate tissue weighting factor $\left(\mathrm{w}_{\mathrm{T}}\right)$ - that is, $\mathrm{E}=\Sigma \mathrm{w}_{\mathrm{T}} \mathrm{H}_{\mathrm{T}}$. It includes the dose from radiation sources internal and/or external to the body.

\section{equivalent dose (EqD)}

The product of average absorbed dose $\left(\mathrm{D}_{T, R}\right)$ in rad (or gray) in a tissue or organ $(T)$ and a radiation $(R)$ weighting factor $\left(\mathrm{w}_{\mathrm{R}}\right)$. For external dose, the EqD to the whole body is assessed at a depth of $1 \mathrm{~cm}$ in tissue; the EqD to the lens of the eye is assessed at a depth of $0.3 \mathrm{~cm}$ in tissue; and the EqD to the extremity and skin is assessed at a depth of $0.007 \mathrm{~cm}$ in tissue. The mathematical term is $\mathrm{H}_{\mathrm{T}}$, while the abbreviation EqD is used in this report and in the REMS reporting requirements for this data element. EqD is expressed in units of rem (or Sv). 


\section{DOE site}

A geographic location operated under the authority of the DOE.

\section{exposure}

As used in this report, exposure refers to individuals subjected to, or in the presence of, radioactive materials that may or may not result in occupational radiation dose.

\section{Hanford}

This term is used to describe the entire reservation and all activities at this geographic location. It includes all cleanup activities at the reactors at the "Hanford Site," ORP, and PNNL. This term is used when we are including Hanford Site, ORP, and PNNL.

\section{Hanford Site}

All activities at, and clean up of, the reactors and 100 - 400 areas at the reservation. Does not include ORP and PNNL.

\section{Office of River Protection}

Tank farm and liquid waste cleanup to protect the Columbia River.

\section{Pacific Northwest National Laboratory}

The national laboratory involved in a broad range of scientific research.

\section{members of the public}

Any individual not occupationally exposed to radiation or radioactive material, who either is not a DOE general employee or is an off duty DOE general employee. The definition of general employee is specified in 10 C.F.R. 835.

\section{number of individuals with measurable dose}

The subset of all monitored individuals who receive a measurable dose (greater than the limit of detection for the monitoring system). Many personnel are monitored as a matter of prudence and may not receive a measurable dose. For this reason, the number of individuals with measurable dose is presented in this report as a more accurate indicator of the exposed workforce. The number of individuals represents the number of dose records reported. Some individuals may be counted more than once if multiple dose records are reported for the individual during the year.

\section{occupational dose}

An individual's ionizing radiation dose (external and internal) as a result of that individual's work assignment. Occupational dose does not include doses received as a medical patient or doses resulting from background radiation or participation as a subject in medical research programs.

\section{rem}

The acronym for roentgen equivalent in man. The rem is equal to 0.01 sievert, which is the international unit of measurement for radiation exposure.

\section{SR (formerly CR)}

SR is defined by United Nations Scientific Committee on the Effects of Atomic Radiation (UNSCEAR) as the ratio of the annual collective dose delivered at individual doses exceeding a specified dose value to the collective dose. UNSCEAR uses a subscript to denote the dose value (in $\mathrm{mSv}$ ) used in the calculation of the ratio. Therefore, $\mathrm{SR}_{15}$ would be the ratio of the annual collective dose delivered at individual doses exceeding 1.5 rems ( $15 \mathrm{mSv}$ ) to the total annual collective dose. 


\section{total effective dose (TED)}

The sum of the ED from external sources and the CED from intakes of radionuclides during the monitoring period. The internal dose component of TED changed from the annual effective dose equivalent (AEDE) to the CEDE in 1993 and from CEDE to CED in 2007.

\section{total number of records for monitored individuals}

All individuals who are monitored and reported to the DOE Headquarters database system. This includes DOE employees, contractors, subcontractors, and members of the public monitored during a visit to a DOE site. The number of individuals represents the number of dose records reported. Some individuals may be counted more than once if multiple dose records are reported for the individual during the year.

\section{total organ dose (TOD)}

The sum of the ED to the whole body for external exposures and the committed equivalent dose to the maximally exposed organ or tissue other than the skin or the lens of the eye.

\section{transient individual}

An individual who is monitored at more than one DOE site during the calendar year.

urinalysis

The technique of determining the amount of radioactive material in the urine excreted from the body. 
This page intentionally left blank. 
1. EPA (U.S. Environmental Protection Agency), 1987. "Radiation Protection Guidance to Federal Agencies for Occupational Exposure," Federal Register 52, No. 17, 2822; with corrections published in the Federal Registers of Friday, January 30, and Wednesday, February 4, 1987.

2. ICRP (International Commission on Radiological Protection), 1977. "Recommendations of the International Commission on Radiological Protection," ICRP Publication 26, Annals of the ICRP, Vol. 1, No. 3 (Pergamon Press, New York).

3. NCRP (National Council on Radiation Protection and Measurements), 1987. "Recommendations on Limits for Exposure to Ionizing Radiation," NCRP 91; superseded by NCRP Report No. 116.

4. ICRP (International Commission on Radiological Protection), 1991. "1990 Recommendations of the International Commission on Radiological Protection," ICRP Publication 60, Annals of the ICRP, Vol. 21, Nos. 1-3 (Pergamon Press, New York).

5. ICRP (International Commission on Radiological Protection), 1994. "Dose Coefficients for Intakes of Radionuclides by Workers," ICRP Publication 68, Annals of the ICRP, Vol. 24, No. 4 (Pergamon Press, New York).

6. 10 C.F.R. 835, 1998, "Occupational Radiation Protection." Rule; DOE Federal Register, November 4, 1998. Amended June 8, 2007.

7. DOE O 231.1B, 2011, "Environment, Safety and Health Reporting," June 27, 2011.

8. REMS Reporting Guide, issued February 23, 2012. Online at http://www.hss.doe.gov/sesa/Analysis/rems/ REMS_Reporting_Guide.pdf.

9. Computerized Accident and Incident Reporting System (CAIRS), "DOE and Contractor Injury and Illness Data by Year by Quarter" report. Online at http://www.hss.doe.gov/sesa/analysis/cairs/cairs/home.htm.

10. DOE Standard, DOE-STD-1098-99 (change notice 1), "Radiological Control," May 2009.

11. DOE O 210.2A, "DOE Corporate Operating Experience Program," April 8, 2011. 


\section{DOE Radiation Exposure Management System (REMS) Dose Abbreviations, Definitions, and Relationships}

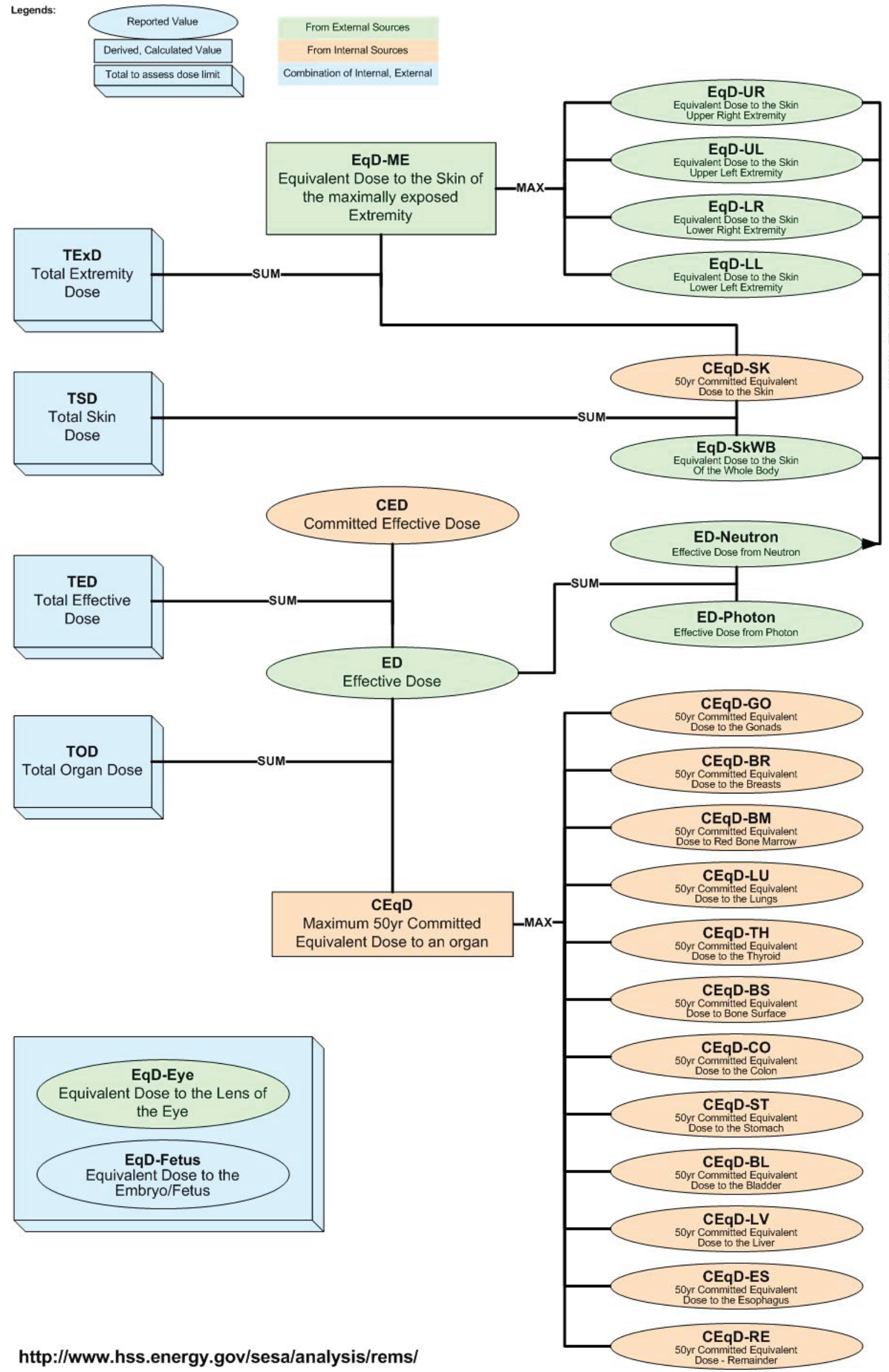




\section{DOE Occupational Radiation Exposure Report}

\section{User Survey}

DOE, striving to meet the needs of its stakeholders, is looking for suggestions on ways to improve the $D O E$ 2012 Occupational Radiation Exposure Report. Your feedback is important. Constructive feedback will ensure the report can continue to meet user needs. Please fill out the attached survey form and return it to:

Ms. Nirmala Rao, Office of Analysis (HS-24) Questions concerning this survey should

DOE REMS Project Manager

be directed to Ms. Rao at (301) 903-2297.

U.S. Department of Energy

1000 Independence Avenue, SW

Washington, D.C. 20585-1290

nimi.rao@hq.doe.gov

Fax: (301) 903-1257

1. Identification:

Name:

Title:.

Mailing Address:

2. Distribution:

2.1 Do you wish to remain on the distribution for the report? yes no

2.2 Do you wish to be added to the distribution? yes no 


\section{Please circle one.}

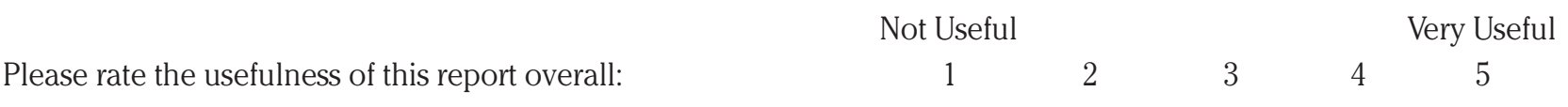

Please rate the usefulness of the analysis presented in the following sections:

\begin{tabular}{|c|c|c|c|c|}
\hline Executive Summary & 1 & 2 & 3 & 4 \\
\hline Analysis of Aggregate Data & 1 & 2 & 3 & 4 \\
\hline Collective Dose & 1 & 2 & 3 & 4 \\
\hline Average Measurable Dose & 1 & 2 & 3 & 4 \\
\hline Dose Distribution & 1 & 2 & 3 & 4 \\
\hline Analysis of Individual Dose Data & 1 & 2 & 3 & 4 \\
\hline Doses above 2 rems ACL & 1 & 2 & 3 & 4 \\
\hline Doses in Excess of 5 rems & 1 & 2 & 3 & 4 \\
\hline Intakes of Radioactive Material & 1 & 2 & 3 & 4 \\
\hline Analysis of Site Data & 1 & 2 & 3 & 4 \\
\hline Collective Dose by Site & 1 & 2 & 3 & 4 \\
\hline Activities Significantly Contributing to Collective Dose & 1 & 2 & 3 & 4 \\
\hline Transient Individuals & 1 & 2 & 3 & 4 \\
\hline Historical Data & 1 & 2 & 3 & 4 \\
\hline ALARA Activities at DOE & 1 & 2 & 3 & 4 \\
\hline Conclusions & 1 & 2 & 3 & 4 \\
\hline Additional Site Descriptions & 1 & 2 & 3 & 4 \\
\hline
\end{tabular}

Please rate the importance of the timeliness of the publication of this report as it relates to your professional need for the information on occupational radiation exposure at DOE:

$\begin{array}{ccccc}\text { Not important } & & & \text { Critical } \\ 1 & 2 & 3 & 4 & 5\end{array}$

Please provide any additional input or comments on the report. 

Prepared for the Office of Health, Safety and Security

by Oak Ridge Associated Universities

P.O. Box 117 • Oak Ridge, TN 37831-0117 